\title{
Synergies between arbitrage and fast frequency response for battery storage systems
}

\author{
Elian Pusceddu', Behnam Zakeri ${ }^{2,3,4}$, Giorgio Castagneto Gissey 1,* \\ ${ }^{1}$ Bartlett School of Environment, Energy and Resources, University College London. \\ ${ }^{2}$ Energy Systems and Efficiency, Aalto University School of Engineering, Finland \\ ${ }^{3}$ Energy Program, International Institute for Applied Systems Engineering, Austria \\ ${ }^{4}$ Sustainable Energy Planning, Aalborg University, Denmark \\ * Corresponding author details: g.castagneto-gissey@ucl.ac.uk; 14 Upper Woburn Place, London WC1H 0NN, UK.
}

\begin{abstract}
Energy storage can make key contributions to balancing future low-carbon energy systems by providing a variety of energy system services, with batteries expected to be widely deployed as costs fall with innovation. This paper assesses whether synergies exist between two of the most significant of these services, fast frequency response and energy arbitrage, if a battery energy storage system (BESS) is used to deliver both. A techno-economic model is developed to simulate 600 possible fast frequency response availability windows. Results show that two distinct synergies exist between the two services. The first synergy accounts for the possibility of charging outside the deadband for delivering fast frequency response. We propose an innovative state-of-charge management strategy to exploit this synergy. The second synergy results from energy arbitrage revenues being highly concentrated around peak times, which can enable a battery system to capture most of the arbitrage revenues without an excessive reduction in revenues from capacity provision with enhanced frequency response. The combination of these two synergies means that a battery system could increase its operating profits by $25 \%$ by delivering arbitrage and frequency response alternately. This result is shown to be statistically robust using historical data. A battery system able to discharge for $1.5-2 \mathrm{~h}$ at its full power rating will most most likely optimise these synergies.
\end{abstract}

Keywords: Energy storage system; battery; ancillary services; battery management strategy; renewable energy; electricity storage.

\section{Highlights}

1. Batteries could provide energy balancing by offering numerous system services

2. Synergies between fast frequency response and energy arbitrage are studied

3. A battery management strategy is developed to leverage value from these services

4. Most arbitrage revenues can be captured without foregoing frequency response payments

5. Delivering enhanced frequency response together with arbitrage can increase operating profits by $25 \%$ 


\section{Abbreviations}

BESS Battery energy storage system

DoD Depth of discharge

EAW EFR availability window

EFR Enhanced Frequency Response

$\mathrm{E} / \mathrm{P} \quad$ Energy-to-power ratio

$E_{n} \quad$ Nominal energy capacity

$M C$ Marginal cost

$M P \quad$ Marginal profit

$M W h_{b}$ Energy bought

$M W h_{s}$ Energy sold

$p_{b} \quad$ Buy price
$P_{n} \quad$ Nominal power capacity

$p_{s} \quad$ Sell price

$P_{\text {target }}$ Target power response

NGET National Grid Electricity Transmission

SPM Service Performance Measure

SoC State of charge

TSO Transmission System Operator

VRE Variable renewable energy

VRFB Vanadium redox flow battery

$\eta_{r t} \quad$ Round-trip efficiency 


\section{Introduction}

The increasing deployment of variable renewable energy (VRE) sources, such as wind and solar, is driving global efforts to reduce greenhouse gas emissions. Yet the challenges this brings to the operation of electricity systems are far from resolved and increase as more VRE is deployed. Variable, non-dispatchable electricity generation makes the complex task of preserving grid stability even more challenging (Strbac et al., 2012) and its impact on wholesale energy markets could cause several technical issues, including unstable frequency (Merten et al., 2020). This could ultimately increase the integration cost of VRE and as such increased electricity prices to consumers (de Sisternes, Jenkins and Botterud, 2016; Goutte and Vassilopoulos, 2019).

Energy storage is widely seen as a key 'enabler' for integrating large volumes of VRE into the grid. Pumped hydroelectric storage is by far the most widely deployed technology to this date, but further uptake is limited by geographical limitations, and a wide range of energy storage technologies are under development with a range of attributes (Brandon et al., 2016). Among these, battery energy storage system (BESS) technologies are envisioned to cover a critical and much greater role (IRENA, 2017). BESSs are not only useful for grid-balancing purposes but also for many other applications. BESSs can be used to arbitrage the daily spread in energy prices (Zafirakis et al., no date), to avoid or defer network-upgrade costs (Poudineh and Jamasb, 2014), and to smoothen the intermittent supply of VRE generators, thereby making their energy more valuable (Lund et al., 2015). Thanks to their versatility and promising potential, some even conjecture that BESSs might represent 'the next energy revolution' (Critchlow and Denman, 2017).

In spite of the multiple value propositions, business cases for BESSs in grid-scale applications have traditionally focused on individual revenue streams in isolation, which is generally found to be insufficient to offset the high technology cost and justify investment (Staffell and Rustomji, 2016). Considering that substantial cost-reductions could be attained through economies of scale (Schmidt et al., 2017), the question is then how to overcome the stalemate hindering the diffusion of BESS and holding back a more rapid deployment of renewable energy sources. 
Some believe that investment in BESS could already be profitable if multiple revenue streams were combined, or 'stacked', together (Fong et al., 2017). However, this is challenged by a number of market and regulatory challenges which reduce the value that storage operators can monetise (Castagneto Gissey et al., 2018). A variety of concepts have been proposed for stacking revenue streams with a BESS: arbitrage can be combined with the provision of balancing services such as reserve and frequency response (Moreira et al., 2016; Staffell and Rustomji, 2016), and also with network services like peak shaving and curtailment avoidance (Chen et al., 2016; Moreira et al., 2016). But establishing which combination of services offers the greatest economic value is not a trivial task, with the answer largely depending on the specific market factors that determine the existence of economic trade-offs or synergies between the different revenue streams. The location of the BESS is also an important factor. For instance, to prevent the curtailment of distributed VRE generation or to provide peakshaving services to distribution network operators, a BESS must be connected to the constrained tracts of the distribution network (Li et al., 2015). Last but not least, an optimal management strategy of BESS to deliver multiple services with different planning horizons and under uncertainty is challenging too (Cho and Kleit, 2015; Moreno, Moreira and Strbac, 2015).

\subsection{Enhanced frequency response: a service for battery storage}

Energy storage systems comprise a wide range of technologies with different technical characteristics. The effectiveness of different energy storage technologies in delivering each possible service is strongly affected by the unique technical properties that each technology offers. For example, compressed air energy storage and pumped hydroelectric storage offer the best value for money for long-duration high-power applications, whereas faster-acting, low-storage size battery technologies are most suited to provide ancillary and balancing services to the grid (Luo et al., 2015). The rapid power modulation of BESSs is highly valuable in the context of provision of frequency response ${ }^{1}$, where a faster response may even decrease the need for the service and hence its overall cost to transmission system operators (TSOs) (NGET, 2018a). It is therefore not surprising that recent technological advances have

\footnotetext{
${ }^{1}$ Frequency response is a quantitative measure of a power system's ability to stabilize frequency immediately following a sudden loss of load or generation.
} 
motivated various TSOs - among which the British National Grid Electricity Transmission (NGET) - to review their balancing market service offering so as to better reward the added value of emerging storage technologies (NGET, 2018b).

The British grid is facing an ever-increasing share of VRE, with the share of wind power hitting $20 \%$ of total electricity demand in 2019 from only $2 \%$ in 2009 . This has raised the need for additional balancing means to respond to frequency deviations in the system. In response to this need, National Grid introduced a new ancillary service called Enhanced Frequency Response (EFR) in 2016, defined as "a service that achieves 100\% active power output at 1 second (or less) of registering a frequency deviation". EFR is comparable with other fast frequency response (FFR) services in different electricity markets, such as primary frequency response (PCR) in Germany and Frequency Containment Reserve - Disturbance (FCR-D) in the Nordic countries (Hollinger, Cortés and Erge, 2018). The grid operator procures the required capacity for EFR through an auction-based mechanism. The results of the first auction show that the eight tenders with 201 MW storage capacity are accepted for 2018 at a total cost of $£ 65.95 \mathrm{~m}$ with an average price of $£ 9.44 / \mathrm{MW}$ of EFR/h (KPMG Energy Advisory, 2016). The existing EFR tender results provide a clear indication of the opportunity this service represents for BESS developers and operators, which will further increase as the UK grid expects to lose up to $20 \%$ of its power grid inertia by 2020, and 40\% by 2025 (Logic Energy, 2019). Due to its recency, the role of BESS in provision of EFR is to date largely understudied. A very few papers have been published on the subject, e.g., (Cooke, Strickland and Forkasiewicz, 2017), none of which assess the potential benefits of alternating the provision of EFR with other services from a storage service provider. This highlights a gap in the literature this study seeks to address. While being similar to other FFR services in Europe and the US, the response time of EFR is significantly shorter, being $<1$ s compared to $<15 \mathrm{~s}$ in PCR in Germany and $<5$ s in FCD-R in other European markets. As such, the results of this paper are not only useful for the examined case study (UK), but also, they can generate insights to inform the regulatory and policy debate on the role of BESS for provision of FFR in other ancillary services markets, including the potential benefits of introducing a very short frequency response service. 


\subsection{Aims, scope, and structure}

Within this context and using the British electricity market as a case study, this study investigates whether the conjunct provision of EFR and arbitrage can improve the business case for BESS. Specifically, this paper addresses the following research questions:

1. Are there synergies between EFR and arbitrage which a BESS could exploit to increase its marginal (or operating) profitability?

2. How sensitive are these synergies to seasonal variations in electricity prices?

3. What technical parameters are most valuable to leverage these synergies?

The paper concerns the optimal use of storage and the key services it can provide, its use and optimization. The remainder of this paper is structured as follows: Section 2 offers a critical review of the literature; Section 3 presents the methodology and introduces the model developed for the purpose of this study; Sections 4 presents the main results; Section 5 discusses them and considers the limitations of this study; finally, Section 6 draws the main conclusions and offers recommendations to exploit the lessons from this study.

\section{Literature review}

The economic value that a BESS can generate through the stacking EFR and arbitrage revenues primarily depends on three factors: (1) the revenues and costs associated with EFR delivery; (2) the daily electricity price profile; and (3) the BESS's ability to always deliver the most remunerative service. Each of these aspects is reviewed below.

\subsection{Enhanced Frequency Response (EFR)}

EFR was designed "to improve management of system frequency pre-fault" (NGET, 2016a). To be eligible for EFR, a BESS must be able to provide symmetric power response to frequency deviations outside the so-called 'deadband', ${ }^{2}$ and to inject or absorb power at its rated capacity for 15 minutes uninterrupted. Although penalties for under-delivery exist, tolerance margins for the required response and ramp-rates are contemplated. Crucially, such margins expressly allow a BESS providing EFR to recharge during EFR provision. It is shown that BESS is one of

\footnotetext{
2 The deadband is a small range around the nominal value where provision of frequency response is not required $( \pm 0.10 \mathrm{mHz})$. It is a measure for insensibility in esmall deviations from the nominal frequency.
} 
the energy storage technologies most suitable for frequency response services (Greenwood et al., 2017).

Due to its recent introduction, the literature studying this service is scarce. ${ }^{3}$ The publications most relevant to this study are reviewed next.

A review of market and regulatory barriers to the diffusion of storage technologies, Castagneto Gissey et al. (2018) note that prohibitively long requirements for energy delivery limit the competitiveness of BESSs in ancillary markets. The authors also stress the importance of flexible market design that rewards speed and accuracy of frequency response for removing barriers to entry for BESSs. These are features that EFR rules specifically reward, which might help explain why all of the winners of the first 200 MW EFR tender were BESS projects (NGET, 2016b).

Compared to arbitrage, and due to the requirement to promptly respond to system frequency changes, EFR delivery is technically more challenging. The evidence so far however suggests that several battery technologies can meet this requirement. For instance, Bahloul and Khadem (2018) devise a power management and control system for a hybrid batterysupercapacitor system and for a BESS alone, and determine that both configurations are capable of adequately meeting EFR requirements. Gundogdu et al. (2018) reach similar conclusions after testing their algorithm in a real-life system.

Economically optimal delivery of EFR is also challenging since a trade-off might be present between high service performance and low state-of-charge $(\mathrm{SoC})$ management cost (Gundogdu et al., 2018). In fact, while the energy exchanges outside of the deadband are free, those within it must be paid for (NGET, 2016a). Several SoC management strategies capable of meeting the service requirements have been proposed. Canevese et al. (2017) consider four strategies ('Cases'). In the first two, the BESS responds to frequency deviations by following (1) the reference response requirement; and (2) the lower envelope ${ }^{4}$ of such requirement. Crucially, the authors find that in both cases the SoC drifts towards full charge. This limits the

\footnotetext{
${ }^{3}$ See Appendix 1 for detail around this search and the discarded literature.

${ }^{4}$ Envelope is a concept used in regulation of power systems, showing the domain for providing flexibility for the management of state of charge of batteries. A "wide" and a "narrow" envelope are defined for EFR, each related to a separate product defined by a) a deadband and b) an allowed $9 \%$ of battery's nominal capacity for charge or discharging actions.
} 
BESS's ability to respond to further power absorption requests, resulting in reduced capacity payments. To address this issue without having to increase the energy-to-power ratio ${ }^{5}(\mathrm{E} / \mathrm{P})$, Canevese et al. introduce a strategy for actively managing the SoC (Case 4) within a narrow range. While they demonstrate that this strategy is sufficient to virtually eliminate underdelivery events, the authors do not to consider alternative ways of handling the 'upward drift' exhibited by the previous Cases, nor do they assess whether this could represent a synergy for the alternate delivery of EFR and other services like arbitrage.

Improving on the above SoC management strategy and building on the control algorithm previously introduced by Gundogdu et al. (2017a), Gundogdu et al. (2017b) and Gundogdu et al. (2018) propose strategies where the SoC target range is adjusted through the day. Gundogdu et al. (2017b) aim to perform arbitrage over real time system prices while managing the SoC within the frequency deadband and find that this strategy can boost marginal profits ${ }^{6}$ by up to $7.5 \%$. Gundogdu et al. (2018) instead focus on the maximisation of Triad avoidance revenues, determining that such an approach has some potential but do not spell out the net improvement this represents. Both studies only investigate a timespan of just a few days, which undermines the statistical significance of their results, especially when combined with the common assumption that system prices are known with perfect foresight. Additionally, they only consider the case of $\mathrm{E} / \mathrm{P}=0.5 \mathrm{~h}$, which may not necessarily be optimal. In addition to the abovementioned, there is a large body of literature on technical aspects and optimal strategies for managing the SoC. Li et al., 2018 proposes a coordinated control strategy considering the variability of wind power and SoC of energy storage to improve the performance of the frequency. In another study (He et al., 2018), a flexible power control strategy is proposed for the coordinated operation of the hybrid ac/dc zones. The benefits of virtual energy storage for frequency response is investigated by Cheng, Sami and $\mathrm{Wu}, 2017$, . However, none of these studies have investigated the market conditions examined in this paper nor considering the aggregation of benefits from arbitrage and frequency response.

In summary, while the ability of various types of BESSs to meet EFR requirements has been abundantly demonstrated, the potential value of (1) alternating EFR delivery with the

\footnotetext{
${ }^{5}$ Canevese $e t$ al. also verify that such issue can be strongly reduced by using BESSs with larger E/P than the required minimum of $0.5 \mathrm{~h}$.

${ }^{6}$ 'Marginal profits' are here referred to interchangeably as 'operating profits' or 'profits'.
} 
provision of other services; and (2) charging outside the deadband have not yet been assessed in the literature and represent the topic of this paper.

\subsection{Arbitrage}

Zafirakis et al. (2016) define arbitrage as a trading strategy to "take advantage of spot market price spreads". Although it is often assumed to occur in the day-ahead markets (e.g. Staffell and Rustomji, 2016; Wilson et al., 2018), arbitrage strategies for intraday markets have also been considered ${ }^{7}$ (Metz and Saraiva, 2018). Multiple studies assessed how to maximise arbitrage profits (e.g. Sioshansi et al., 2009; Staffell and Rustomji, 2016), but the consistent finding is that the attainable revenues are on their own insufficient to repay investment in battery storage.

A standard approach for estimating arbitrage profits is to assume perfect foresight of the electricity prices, which necessarily provides an over-estimate of the profits achievable in practice. Staffell and Rustomji (2016) for instance find that $75 \%-88 \%$ of the perfect-foresight revenues can be attained through a price-forecasting method solely based on historical data. ${ }^{8}$ More sophisticated approaches employing techniques based on stochastic optimisation have also been proposed to more realistically simulate the scheduling decision (Saravanan et al., 2013), yet these add substantial modelling complexity.

The economic value that a BESS operator can derive from arbitrage depends on a mix of technical and market factors. Among the former, round-trip efficiency has arguably the largest impact on the economic value of arbitrage as efficiency losses are the major contributor to the marginal cost of operating a BESS. ${ }^{9}$ Another important parameter is the discharge capacity, or energy-to-power ratio for a fixed power capacity, which determines how much energy can be stored in a BESS. Due to a combination of physical and operational stress factors, ${ }^{10}$ discharge capacity tends to fade over the 'lifetime'11 of the asset, assuming special importance in

\footnotetext{
${ }^{7}$ Seasonal storage is also possible, but since this application is not considered economically viable for BESSs (Beaudin et al., 2010) it is not investigated further here.

8 The upper bound being for round-trip efficiencies of $100 \%$.

${ }^{9}$ As discussed in Section 3.3.

10 A key stress factor is the depth of discharge, the impact of which depends on the specific chemistry of the BESS (Xu et al., 2017).

11 The number of useful cycles before the discharge capacity fades to a threshold (often $80 \%{ }^{11}$ ) below which asset replacement is deemed necessary.
} 
determining the asset's profitability (He et al., 2020). While the cost of replacement is only incurred at the end of a BESS's lifetime, Xu et al. (2017) note that, since the rate of ageing depends on operational factors determined by the specific operating strategy pursued, ageing should also be factored into the marginal cost function, which can sometimes have major repercussions on the operating strategy itself.

Concerning the market factors that affect the profitability of arbitrage, it is generally accepted that it is primarily price volatility, rather than mean prices, that influence its value (Wilson et al., 2018).

\subsection{Revenue stacking}

While the reviewed literature confirms that BESSs can be used for both arbitrage and EFR, the extent to which their joint provision might yield economic benefits remains unclear. Abstracting from EFR, the topic of revenue stacking has received great attention in the literature. Studies have considered the stacked delivery of arbitrage and primary or secondary frequency response (e.g. Kreikebaum et al., 2011; Fong et al., 2017); arbitrage and reserve $^{12}$ (e.g. Loisel et al., 2010; Staffell and Rustomji, 2016); arbitrage and network services (Moreira et al., 2016; Teng and Strbac, 2016; Fong et al., 2017); and network services and frequency response (Shi et al., 2017). In the context of BESSs co-located with VRE sources, the additional value arising from imbalance penalty reduction has also been considered (Korpaas et a Belli et al., 2017). While it is not typically necessary to model imbalances in the case of a BESS delivering arbitrage, $^{13}$ when services with uncertain utilisation are also offered, it is appropriate to account for these.

The basic principle behind revenue stacking is that a BESS can be better utilised when providing multiple services provided these do not have conflicting demands. Starting from this observation, and using historical data for 2012, Moreira et al. (2016) quantify the interactions or 'synergies' between arbitrage, peak shaving, and various balancing services. Their findings highlight that such synergies are highly dependent on the correlation between market and system operating conditions, which generally depends on the time of day and

\footnotetext{
12 In these studies, compressed air energy storage (CAES), rather than battery storage, is usually considered for reserve applications, due to its greater cost-effectiveness at much larger energy capacities.

13 This is because the scheduling process is fully under the control of the storage operator.
} 
season. An exception to this relates to the upwards balancing and peak shaving services, between which an overwhelming synergy exists (Shi et al., 2017).

Based on the insights from Moreira et al., the time-dependence of potential synergies between EFR and arbitrage represents a specific focus of the present study. While Moreira et al. provide useful insight into synergies and conflicts between services, their study relies on a sophisticated black-box model, ${ }^{14}$ which makes it difficult to extend their analysis to study other interactions. On the contrary, Staffell and Rustomji (2016) develop a much simpler model to optimise arbitrage profits while also delivering reserve, and enclose the core optimisation algorithm within their publication for others to use. This provides the starting point for the model developed in this study, which is presented hereafter.

\section{Methodology}

A techno-economic model was built in $\mathrm{MATLAB}^{15}$ to answer the research questions set out above. The model can simulate the operation of BESSs of any size and type in the delivery of frequency response and price arbitrage. In the examined power system, electricity is traded in a day-ahead market. The system operator is responsible for maintaining frequency response through available capacity resources procured for a contracted period of one year. The developed model is applicable to the case that the day-head electricity prices and required capacity for frequency response are known to the battery owner. Knowing the electricity prices in the upcoming $24 \mathrm{~h}$, an optimal strategy can be derived for benefiting from charging in low-price hours and discharging when the prices are high, by enforcing physical constraints and simulating the effects of ageing on discharge capacity (Section 3.1). In addition, BESS charge-discharge scheduling is co-optimized with the benefits that it can gain from EFR. For this purpose, the required capacity and compensation prices for provision of EFR are from historical data and fed as input data to the model. EFR and wholesale electricity market Therefore, the main contribution of this paper can be specified as:

\footnotetext{
14 This is the mixed integer linear programming algorithm introduced in a previous publication by Moreno et al. (2015).

15 The MATLAB source code of the techno-economic model is provided in full as an attachment to this paper.
} 
- Proposing a new methodology for managing the state of charge of BESS during provision of EFR: specifically to exploit the synergies between EFR and arbitrage while ensuring compliance with EFR rules (Section 3.2);

- Designing an algorithm to optimise arbitrage profits: This was adapted from a previous algorithm by Staffell and Rustomji (2016) to account for the predicted and actual energy utilisation through each EFR availability window (EAW), and also to model the impact of imbalances against the scheduled power profile (Section 3.3); and

- Developing financial evaluation routines to calculate the contributions of the multiple revenue and cost drivers to the overall economic performance of the BESS (Section 3.4).

The high-level functioning of the model is summarised in Figure 1, which also presents the main steps of the overarching algorithm used to compute results reported in Section 4. The next sub-sections describe the key aspects of the model and the data used.

\subsection{Techno-economic model}

A BESS with $10 \mathrm{MW}$ symmetric power capacity and varying energy-to-power ratios (E/P) was chosen for this study. ${ }^{16}$ Two BESS archetypes were developed, one representing a Vanadium redox flow battery (VRFB) and one a Lithium-ion battery. These technologies were selected because they are considered among the prime candidates for grid-scale storage (Schmidt et al., 2017), and because their different value propositions, and specifically differences in roundtrip efficiency and lifetime, enable an analysis of the impact of these components on the value of the operating model assessed here.

\footnotetext{
16 This chosen size is representative of contracted EFR tenderers (NGET, 2016b), whereas response symmetry is a specific tender requirement. The $\mathrm{E} / \mathrm{P}$ ratio is defined by the nominal $\mathrm{E}$ and $\mathrm{P}$ values decreasing over time due to ageing.
} 


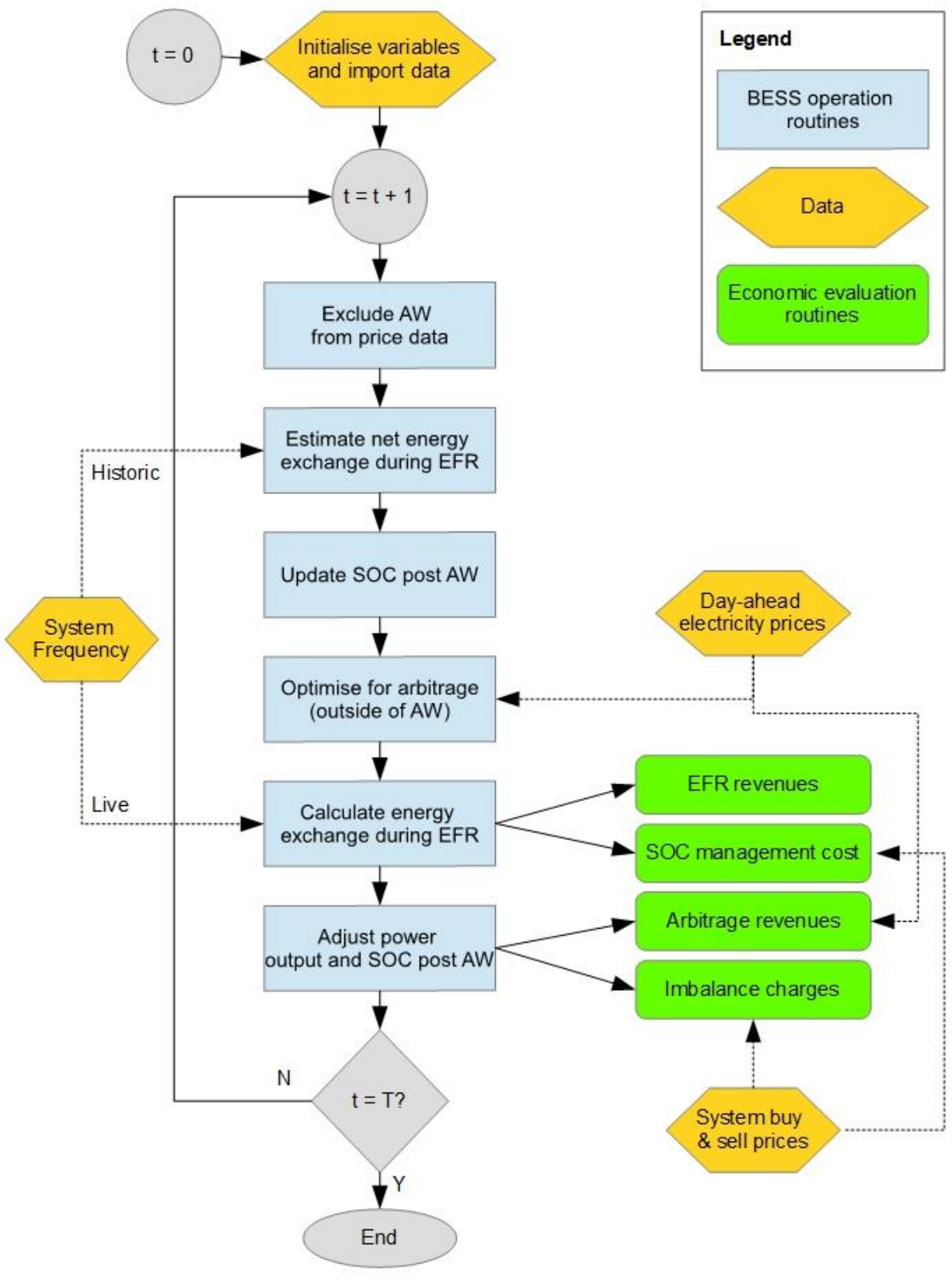

Figure 1 - BESS scheduling and economic evaluation model.17

Representative values for the key techno-economic parameters were selected based on the literature on battery technologies in general (Luo et al., 2015; Zakeri and Syri, 2015) and that of VRFB and Lithium-ion specifically (Hesse et al., 2017; Minke, Kunz and Turek, 2017). These are summarised in Table 1.

17 This and the other figures presented here the author's own work, unless otherwise specified. 
Neither upfront technology costs nor fixed operating costs are modelled in this study since they do not affect the marginal cost function and the operating strategy.

Table 1 - Values for key techno-economic parameters for selected BESS technologies.

\begin{tabular}{|l|c|c|}
\hline Parameter & Lithium-ion & VRFB \\
\hline Round-trip efficiency & $90 \%$ & $80 \%$ \\
\hline Lifetime $^{18}$ [\# cycles] & 5,000 & 20,000 \\
\hline Marginal cost of ageing $^{19}[£ / \mathrm{MWh}]$ & 1.8 & 0.8 \\
\hline Energy-to-power ratio (E/P) [hours] & $1-2.5$ & $1-2.5$ \\
\hline
\end{tabular}

\subsubsection{Physical constraints}

To simulate the operation of the BESS in a realistic way, the following physical constraints are enforced by the model. The input/output power $P$ is constrained in its absolute value by the nominal power capacity $P_{n}$ (Eq. 1). The charge level is limited between zero and the nominal energy capacity $E_{n}$, or between 0 and 1 when expressed in terms of the state of charge, $S o C$ (Eq. 2). Its derivative is in turn always linked to the instantaneous power $P_{n}(t)$ (Eq. 3). ${ }^{20}$

$$
\begin{gathered}
\operatorname{abs}(P(t)) \leq P_{n} \\
0 \leq \operatorname{SoC}(t) \leq 1 \\
E_{n} \frac{d}{d t} \operatorname{SoC}(t)=\eta_{r t} P_{\text {in }}(t)+P_{\text {out }(t)}
\end{gathered}
$$

Technical ramp-rate limitations are instead neglected since the evidence reviewed suggests that BESSs are generally capable of the ramp rates necessary for the applications studied here (Canevese et al., 2017; Bahloul and Khadem, 2018). Market constraints relevant to EFR are discussed in Section 3.2.

\footnotetext{
18 i.e. The number of cycles to $80 \%$ capacity fading (Hesse et al., 2017).

19 Original values by Zakeri and Syri (2015) where converted using an exchange rate of $1.15 € / €$.

20 The convention of referring $E_{n}$ and $S o C$ to the MWh discharged is employed here, hence the efficiency factor preceding $P_{\text {in }}(t)$, and none preceding $P_{\text {out }}(t)$.
} 


\subsubsection{Ageing and capacity fading}

As previously mentioned, only those factors affecting the marginal cost of operation $(M C)$ must be accounted for to simulate the BESS operating strategy. ${ }^{21}$ In addition to the cost of the energy purchased while charging, discussed in Section 3.3, it is assumed here that the cost of ageing is the most significant contributor to the marginal cost of the BESS. This assumption is based on the insights offered by Zakeri and Syri (2015) and Xu et al. (2017) concerning the primary, yet an often neglected, contribution of ageing to the marginal cost. Marginal cost of aging is primarily the replacement cost of battery modules after certain number of operating cycles, either at entirety or partial replacement of electrochemical components.

To quantify the marginal cost of ageing $\left(M C_{\text {ageing }}\right)$, $\mathrm{Xu}$ et al. (2017) pro-rate the BESS replacement cost to each individual cycle through a piecewise linear function of the depth-ofdischarge (DoD), derived on experimental data for Lithium-ion batteries. Instead, Canevese et al. (2017) employ life-cycle curves also expressed as a function of the DoD. In both cases, an iterative process is required to determine the appropriate value for ageing-related costs, since the $\mathrm{DoD}$ is dependent on the output power, and the output power at each period is only finalised after the schedule optimiser has iterated through an entire day, for which knowledge of the DoD at each time-period is required. Considering that excessive ageing can usually be mitigated by containing the $\mathrm{DoD}^{22}$ (Xu et al., 2017), and also considering the lack of comparable data for VRFBs, this study opts for a simplified approach based on the work of Zakeri and Syri (2015): the marginal cost of ageing is assumed to be independent of the DoD and equals $€ 2.1 / \mathrm{MWh}$ and $€ 0.9 / \mathrm{MWh}$ for Lithium-ion and VRFB, respectively. ${ }^{23}$ In this method, the number of replacements of the battery modules are estimated based on the required operating cycles of the battery for a given service. For example, a battery with 1000 nominal operating cycles needs three replacements for providing a service with one charge-discharge cycle per day (= 365 per year) and the lifetime of 10 years (a total 3650 cycles). Therefore, the cost of battery replacement is divided by the estimated number of operating cycles to calculate the

\footnotetext{
${ }^{21}$ Other operating costs not modelled here are e.g. the energy demand for the power control system and the cost of maintenance. Both being fixed costs, they do not affect the marginal cost, MC.

${ }^{22}$ Although this results in a higher capacity rating and hence higher capital cost for the same application.

23 See footnote 19 .
} 
additional marginal cost related to replacement, so called marginal cost of aging, for each MWh energy discharged by BESS.

Ageing also leads to progressive reduction in the discharge capacity of most BESSs, a phenomenon also known as capacity fading. Capacity fading reduces the economic value that can be derived from a BESS, hence its impact was also modelled in this study. The energy capacity was assumed to decrease linearly with every cycle reaching $80 \%$ of its original value after the lifetime indicated for each technology in Table $1 .{ }^{24}$ The number of cycles was calculated retrospectively at the end of each day based on actual cycling. ${ }^{25}$ Other more ancillary assumptions are discussed in Appendix 2.

\subsection{A new state-of-charge management strategy for Enhanced Frequency Response}

One of the main contributions of this study is the novel SoC management strategy, specifically designed to maximise the amount of recharging that a BESS can attain at no cost while it provides EFR. Zero-cost or 'free' charging is allowed by EFR rules (NGET, 2016a) when two conditions are met. First, the system frequency must be outside the deadband region confined by points $C$ and $D$ in Figure 2, the frequency values of which are provided in Table 2. Second, the frequency must be within the range where the minimum allowed power output from the BESS - defined by the lower service envelope, or 'Envelope Lower' - is negative. The area where free charging is allowed is shaded in green in Figure 2 . The novel strategy proposed in this study is discussed in detail in Section 3.2.1.

Second-by-second system frequency data for the 2015-2017 period was obtained from NGET (2018) and was used to model the instantaneous power demand during each EFR availability

\footnotetext{
${ }^{24}$ It is also noted that, for VRFBs in particular, the already low impact of ageing could be virtually eliminated through the use of innovative ion-exchange membranes (Oldenburg, Schmidt and Gubler, 2017).

${ }^{25}$ For transparency, the impact of the DoD on the rate of ageing was neglected. Hence, the impact of e.g. five cycles between SoC of 0.4 and 0.6 are modelled as having the same impact as a single full cycle (i.e. SoC changing from 0 to 1 , and back).
} 
window $(\mathrm{EAW})$. The use of historical data was preferred to the use of power-system simulations ${ }^{26}$ because it ensures a statistically accurate modelling of the power demands. ${ }^{27}$

The instantaneous power response from the BESS is limited by the power and ramp-rate constraints set by NGET (2016a), since financial penalties apply in case either the power response or the ramp-rate constraints are violated.

There are two different sets of constraints depending on whether wide- or narrow-band EFR is offered. Wide-band EFR, so called 'Service 1', defines the frequency deadband as between 49.95 and $50.05 \mathrm{~Hz}$ (a range of $0.1 \mathrm{~Hz}$ ), whereas narrow-band EFR or 'Service 2' defines the frequency deadband as between 49.985 and $50.015 \mathrm{~Hz}$. This is a much narrower range (of 0.03 $\mathrm{Hz}$ ) than that allowed by Service 1. The narrower band of Service 2 also corresponds to tighter and more challenging operating requirements, since the BESS has more limited time to return to its target SoC during the deadband. Regardless of which EFR service is provided, the BESS' power response must always fall within the upper and lower envelopes characterised by points A-F and t-z in Figure 2, numerical values for which are reported in Table 2 and Table 3.

The ramp-rate constraints reported in Table 4 instead depend on both system frequency and the power output from the BESS, which leads to the definition of the A-D regions illustrated in Figure 3.

A more extensive discussion of these constrains is offered by Gundogdu et al. (2017a). ${ }^{28}$ Financial penalties arising in case of violations of these constraints were also modelled. ${ }^{29}$ Additionally, the extended frequency event control system developed by Gundogdu et al. (2017a) was implemented to maximise the BESS's availability, yet the author's finding that this is only rarely triggered was confirmed.

\footnotetext{
26 An option discussed in Section 5.3.

27 The statistical relevance is derived by the fact that all data used here refers to the same market (Great Britain) and to the same period.

28 Appendix 3 shows an example of the ramp-rates attained in practice with the present strategy.

29 Such violations only occur when the charge level is too low (high) for the BESS to respond to further power injection (absorption) requests.
} 


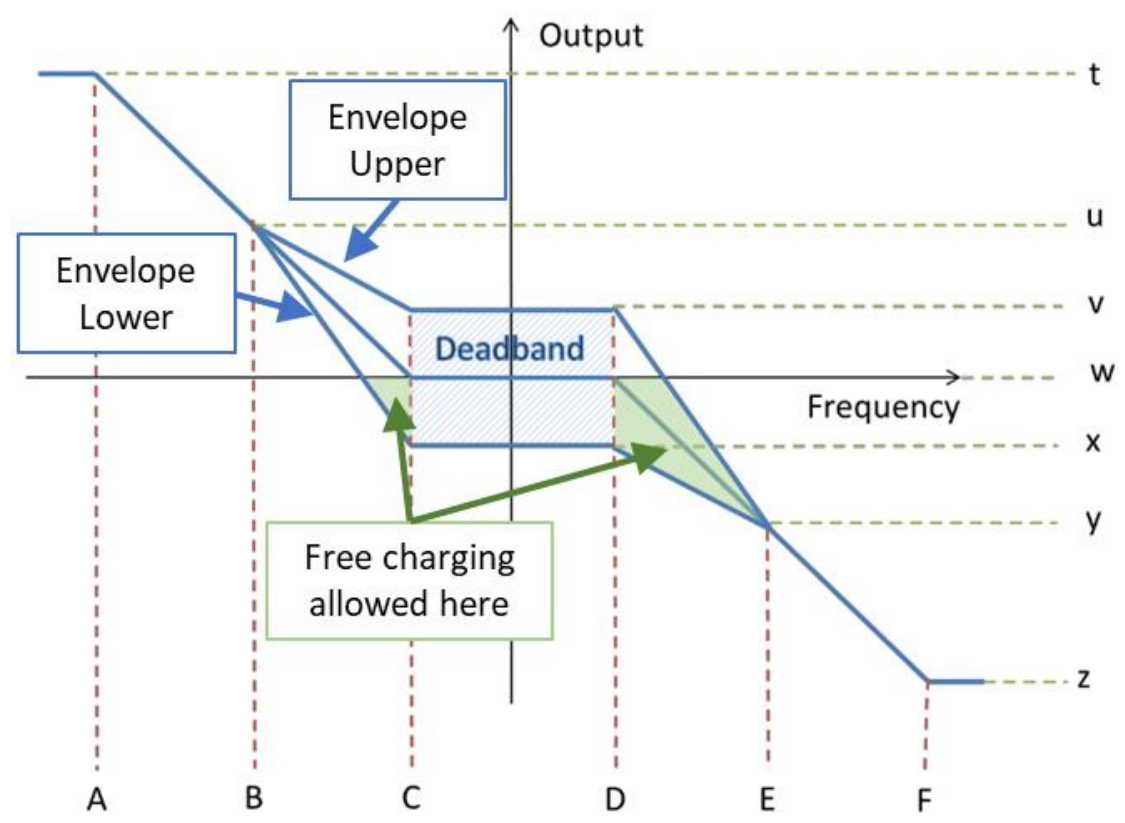

Figure 2 - EFR service envelopes, ${ }^{30}$ adapted from NGET (2016a).

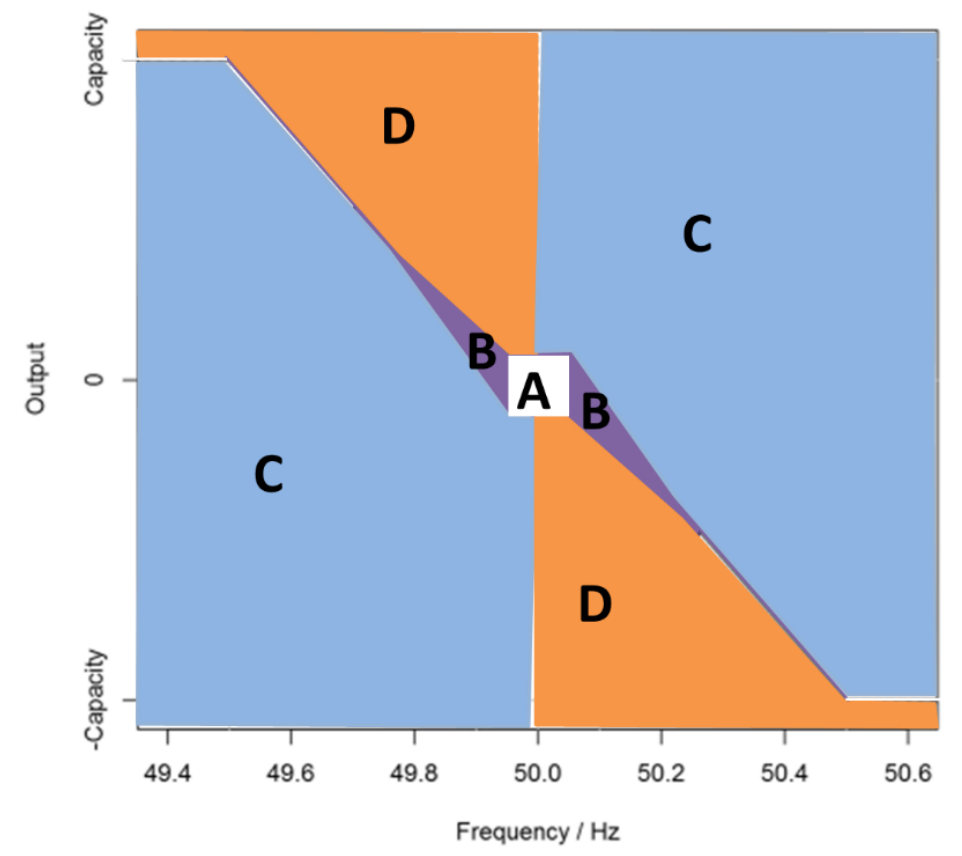

Figure 3 - EFR areas for ramp-rate definition purposes. Source: NGET (2016a).

${ }^{30}$ Envelope Upper and Envelope Lower are the formal names used by NGET (2016a). 
Table 2 - Reference system frequencies.

\begin{tabular}{|c|c|c|}
\hline $\begin{array}{c}\text { Reference } \\
\text { Point }\end{array}$ & $\begin{array}{c}\text { Service } \mathbf{1} \\
\mathbf{( H z )}\end{array}$ & $\begin{array}{c}\text { Service } 2 \\
\mathbf{( H z )}\end{array}$ \\
\hline A & 49.5 & 49.5 \\
\hline B & 49.75 & 49.75 \\
\hline C & 49.95 & 49.985 \\
\hline D & 50.05 & 50.015 \\
\hline E & 50.25 & 50.25 \\
\hline F & 50.5 & 50.5 \\
\hline
\end{tabular}

Table 3 - Normalised Response requirements.

\begin{tabular}{|c|c|c|}
\hline $\begin{array}{c}\text { Reference } \\
\text { Point }\end{array}$ & $\begin{array}{c}\text { Service 1 } \\
\text { (\% Capacity) }\end{array}$ & $\begin{array}{c}\text { Service 2 } \\
\text { (\% Capacity) }\end{array}$ \\
\hline $\mathrm{t}$ & $100 \%$ & $100 \%$ \\
\hline $\mathrm{u}$ & $44.44444 \%$ & $48.45361 \%$ \\
\hline $\mathrm{v}$ & $9 \%$ & $9 \%$ \\
\hline $\mathrm{w}$ & $0 \%$ & $0 \%$ \\
\hline $\mathrm{x}$ & $-9 \%$ & $-9 \%$ \\
\hline $\mathrm{y}$ & $-44.44444 \%$ & $-48.45361 \%$ \\
\hline $\mathrm{z}$ & -100 & -100 \\
\hline
\end{tabular}

Table 4 - Maximum and minimum ramp-rates as a percentage of Operational Capacity (MW/s).

\begin{tabular}{|c|c|c|}
\hline Area & Maximum Ramp Rate & Minimum ramp Rate \\
\hline A & $1 \%$ & $0 \%$ \\
\hline C & $200 \%$ & $0 \%$ \\
\hline D & $10 \%$ & $0 \%$ \\
\hline B (Service 1) & $\left(-\frac{1}{0.45} d f / d t+0.01\right) * 100$ & $\left(-\frac{1}{0.45} d f / d t-0.01\right) * 100$ \\
\hline B (Service 2) & $\left(-\frac{1}{0.485} d f / d t+0.01\right) * 100$ & $\left(-\frac{1}{0.485} d f / d t-0.01\right) * 100$ \\
\hline
\end{tabular}

\subsubsection{How the new strategy works}

As noted by Canevese et al. (2017), continuous EFR delivery often necessitates active SoC management when the system frequency returns to the deadband ${ }^{31}$ This in turn implies that a cost must be borne by the battery operator, since energy exchanges in the deadband must be paid for (NGET, 2016a). However, it was noted earlier that partial SoC management can be attained nearly free-of-charge outside the deadband..$^{32}$ Building on this observation, a SoC management strategy designed to maximise the amount of charging outside the deadband was implemented in the model. The algorithm on which this strategy is based is illustrated in Figure 5 . At each time step (from $\mathrm{t}=0$ to $\mathrm{t}=\mathrm{T}$ ) the algorithm starts by reading the real-time system frequency $f(t)$ and checking whether this is within the deadband (DB) or not.

If the system frequency is in the deadband, the algorithm checks whether the current SoC is above a high-SoC threshold $\left(\mathrm{SoC}_{\mathrm{H}}\right)$ or below a low-SoC threshold $\left(\mathrm{SoC}_{\mathrm{L}}\right)$. If the former, the algorithm sets a target power response ( $\mathrm{P}_{\text {target}}$ ) that is equal to discharging at the rated power

\footnotetext{
31 i.e., An absolute deviation from $50 \mathrm{~Hz}$ of less than $0.015 \mathrm{~Hz}$ in Service 1 and of less than $0.05 \mathrm{~Hz}$ in Service 2. 32 See Section 2.1.
} 
$\left(\mathrm{P}_{\mathrm{n}}\right)$ so that the BESS can return to within its optimal SoC state as rapidly as possible. If the latter, $\mathrm{P}_{\text {target }}$ is instead set to be equal to charging at the rated power. If the SoC is instead within the low- and high-SoC threshold the BESS remains idle $(\mathrm{P}=0)$. In all cases it is noted that the actual power response $\mathrm{P}$ may differ from $\mathrm{P}_{\text {target }}$ due to the envelope and ramp-rate constraints defined in Table 3 and Table 4 and enforced in the last algorithm step.

If the system frequency is instead outside of the deadband, the algorithm always aims to charge at the maximum power allowed while respecting envelope and ramp-rate constraints. This is the key feature that ensures that the maximum amount of free charging is attained whenever the system frequency falls within the region specified at the start of this section.

Figure 4 shows the extent to which the proposed state-of-charge management strategy enables increased charging during an illustrative 4-hour EAW, compared to a strategy that strictly follows the reference envelope (i.e., the mid-point of the upper and lower envelopes). In both cases, the initial SOC at the beginning of the EAS is around 0.4 and the frequency deviation $\Delta \mathrm{f}$ is the same. The SoC would have reduced to 0.32 by the end of the EAW when following the reference envelope. Instead, it increases to 0.48 when following the proposed SoC management strategy. Thanks to the zero-cost charging, this makes it possible for the BESS to discharge a larger amount of energy in the arbitrage market when the EAW is over, and this underpins the economic benefit of the strategy proposed in this study. This strategy's ability to fully comply with EFR ramp-rate restrictions is demonstrated in Appendix 3. 


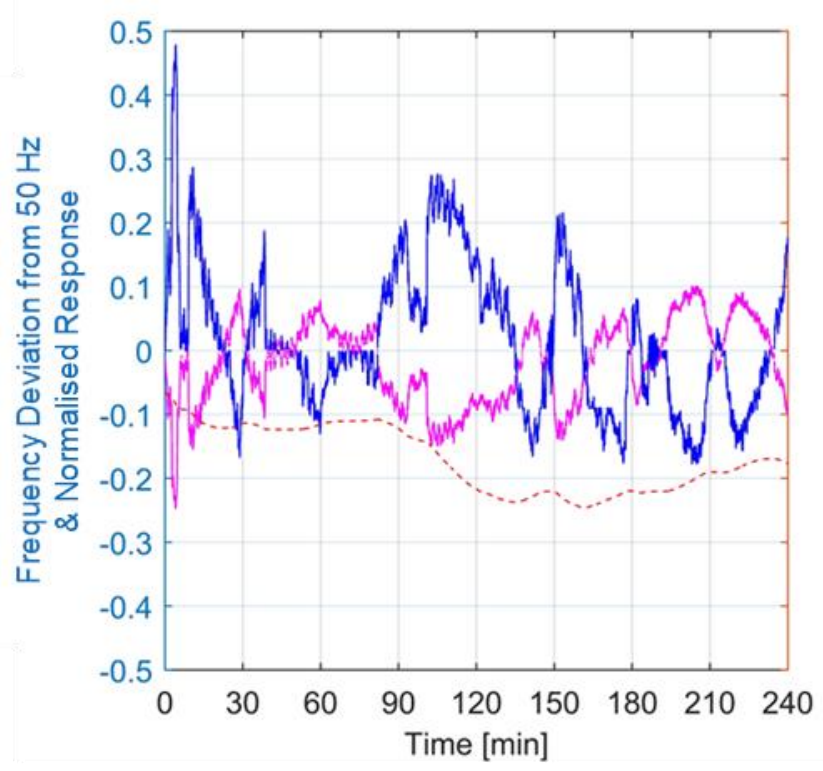

(a) NR = reference envelope

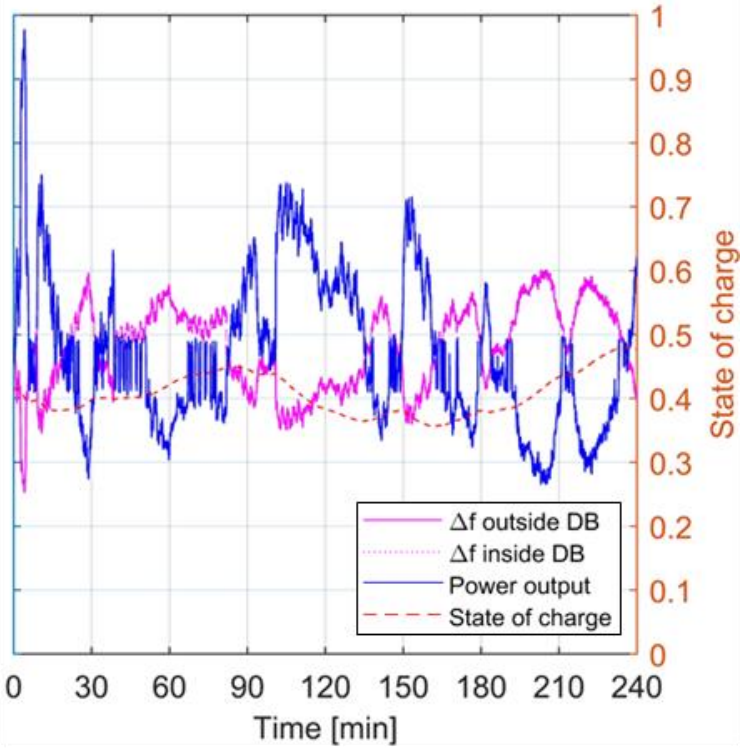

(b) New SoC management strategy

Figure 4 - Impact of the new SoC management strategy on the charge level change across a 4-hour availability window. 


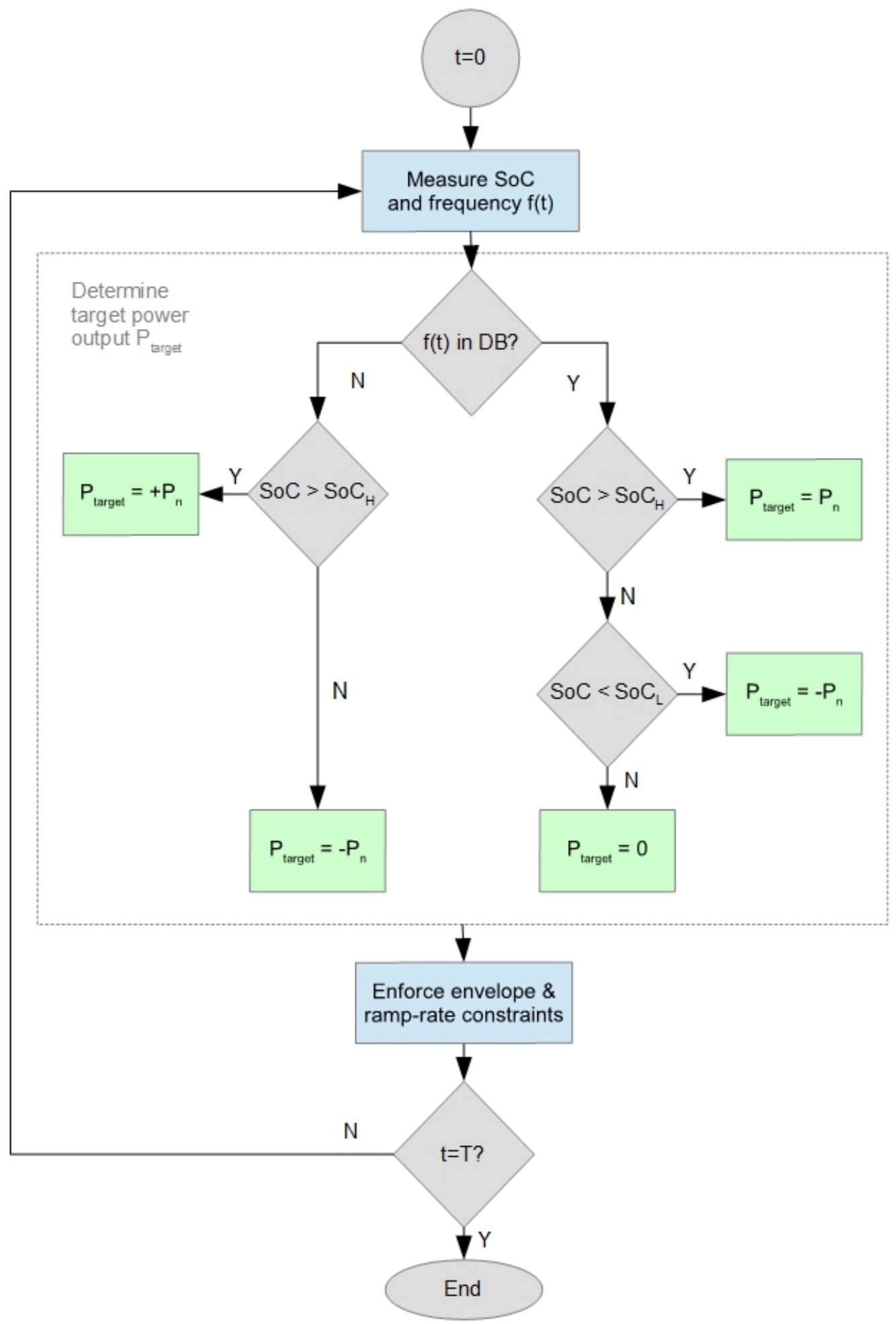

Figure 5 - Control algorithm for the new SoC management strategy. ${ }^{33}$

${ }^{33} S o C_{H}$ and $S o C_{L}$ are defined in (Eq. 7). 


\subsection{Optimising for arbitrage outside of Enhanced Frequency Response availability windows}

Arbitrage is assumed to occur in the day-ahead market, where most energy volumes are traded $^{34}$ (Wilson et al., 2018). Historical market data for 2015-2017 from the N2EX day-ahead auction (Nord Pool, 2018) was used for this purpose. ${ }^{35}$ Additionally, historical data for the balancing mechanism was obtained for the same period from Elexon (2018). ${ }^{36}$ Following the common approach that enables substantial simplification within the profit-optimising algorithm, perfect foresight over day-ahead prices was assumed. ${ }^{37}$

An algorithm to optimise for arbitrage profits while accounting for the predicted and actual energy utilisation through each EAW was implemented in the model. This was adapted from previous work by Staffell and Rustomji $(2016)^{38}$ to also account for the predicted and actual utilisation through EFR and to reflect the financial impact of potential imbalances against the scheduled power profile. As shown in Figure 6, the algorithm matches the highest- and lowest-price periods defined by their indexes $i_{M A X}$ and $i_{M I N}$, respectively, and shifts the largest possible volume of energy between the two. This process will be repeated until all periods where arbitrage is profitable are exhausted. As described in detail in the supplementary material by Staffell and Rustomji (2016), the maximum energy volume that can be shifted between any two periods - the 'bottleneck' - is constrained by: 1) the residual MW capacity in each of the two periods, after accounting for previously scheduled power capacity; and 2) the maximum MWh capacity available for charging at any period between the charge and discharge periods. ${ }^{39}$

\footnotetext{
34 Outside the bilateral contract market.

35 This time series includes weekends and is provided on an hourly basis.

${ }^{36}$ As an alternative, it would have been possible to model day-ahead price fluctuations via a power system simulation as done for instance by Loisel et al. (2010), but since Moreira et al. (2016) demonstrate that the synergies between different services are strongly dependent on their statistical characteristics, the use of historical - and hence statistically consistent - data was preferred.

37 The implications of this assumption and possible alternatives are discussed in Section 5.3.

38 Itself build on the work by Lund et al. (2009).

39 The description of this second constraint assumes that charging occurs before discharging, but the opposite might be true: if so, simply replace 'maximum' with 'minimum' and swap 'charge' or 'charging' with 'discharge' or 'discharging'.
} 


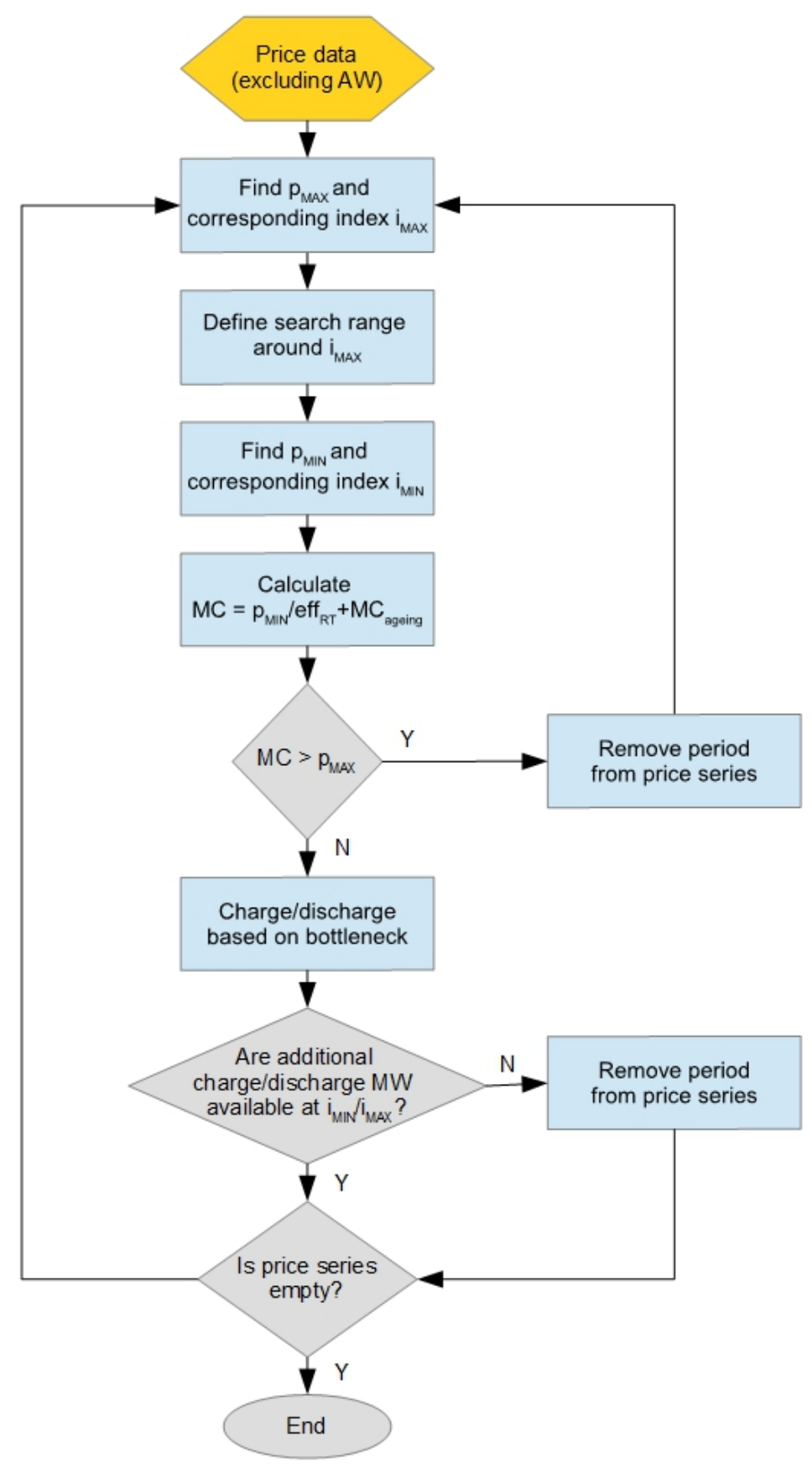

Figure 6 - Arbitrage optimisation algorithm. Adapted from Staffell and Rustomji (2016).

The key decision point in this algorithm is represented by the test of whether a discharge period's price is higher than the marginal cost of operation $(M C)$, which is expressed by:

$$
M C=M W h_{b} * p_{b}+M C_{\text {other }}
$$


where $p_{b}$ and $M W h_{b}$ are the price and volume of energy that needs to be bought to fulfil the discharge requirement. ${ }^{40}$ As discussed in Section 3.1.2, the assumption $M C_{\text {other }} \cong M C_{\text {ageing }}$ is made in this study, and since $1 / \eta_{r t}$ units of energy must be bought for each unit sold the final expression for the marginal cost can be rewritten as: ${ }^{41}$

$$
M C=\frac{M W h_{s}}{\eta_{r t}} p_{b}+M C_{\text {ageing }}
$$

\subsubsection{Optimising the state-of-charge at the start of each availability window}

To avoid excessive drifting of the SoC over time, ${ }^{42}$ the target SoC at the start of each EAW $\left(S o C_{k}\right)$ was constrained to return within $5 \%$ of the exogenously set initial SoC $\left(S_{0} C_{0}\right)$ (Eq. 6). Values for $S_{o} C_{0}$ where selected in compliance with EFR rules (NGET, 2016a), which required the BESS to be available for a continuous response of at least $15 \mathrm{~min}$ at its rated power (Eq. 7). ${ }^{43}$ Both constraints were implemented as part of the arbitrage optimisation algorithm described in Figure 6:

$$
\begin{gathered}
\operatorname{SoC}_{0}-5 \% \leq \operatorname{SoC}_{k} \leq \operatorname{SoC}_{0}+5 \% \quad \text { for } k=24,48,72 \ldots \\
\operatorname{SoC}_{L}=\frac{15 \mathrm{~min}}{E_{n} / P_{n}} \leq \operatorname{SoC}_{0} \leq 1-\frac{15 \mathrm{~min}}{E_{n} / P_{n}} \eta_{r t}=\operatorname{SoC}_{H}
\end{gathered}
$$

Finally, the optimal $S_{0} C_{0}$ for each EAW was determined by varying these parameters over a grid of values and then selecting the one yielding the maximum net operating profit.

\subsection{Financial evaluation}

As outlined in Figure 1, four revenue and cost drivers contribute to the BESS's financial performance. Specifically, the BESS earns an arbitrage profit as well as hourly capacity payments for EFR, modelled in this study as being $£ 10 / \mathrm{MW} / \mathrm{h}$, which is an average value of the accepted tenders in $2018 .{ }^{44}$ To obtain the overall EFR revenue, the capacity payment is

\footnotetext{
40 With reference to Figure 6 and (Eq. 4 ), $p_{b}=p_{M I N}$ and $p_{s}=p_{M A X}$.

${ }^{41}$ It is noted that, for typical values $p_{b}=£ 40 / M W h, \eta_{r t}=90 \%$, and $M C_{\text {ageing }}=£ 0.8-1.8 / M W h$ (see Table 1), the first term on the right-hand side of (Eq. 5) is 25-55 times higher than the second.

42 Which was seen to negatively affect the BESS utilisation and its profitability.

43 See footnote 21 for a justification of the positioning of $\eta_{r t}$.

${ }_{44}^{4}$ In line with the rates contracted to the eight winners to the first EFR tender - all BESSs - who receive between

$£ 7-12 / \mathrm{MW}$, with an average of $£ 9.44 / \mathrm{MW}$ (NGET, 2016b).
} 
multiplied by an Availability Factor calculated from the Service Performance Measure (SPM) as shown in Table 5. The SPM itself is calculated by averaging the second-by-second performance measure (SBSPM) over each settlement period (Eq. 8). The SBSPM is calculated as the absolute deviation between the normalised response $(N R)$ and the nearest envelope at the time when the frequency was measured,,$^{45}$ or simply equal to 1 if $N R$ lies within the envelopes in Figure 2 (Eq. 9). Finally, both imbalance charges and SoC energy management costs are calculated using historical system prices (Elexon, 2018). ${ }^{46}$

$$
\begin{gathered}
\mathrm{SPM}=\frac{\Sigma_{\mathrm{s}}^{\mathrm{j}} S B S P M_{S}}{1800} \\
S B S P M_{S}=1-\operatorname{abs}\left(\mathrm{NR}_{\mathrm{s}+1}-\text { nearest envelope }{ }_{s}\right)
\end{gathered}
$$

Table 5 - Availability factors for capacity payment calculation. Source: NGET (2016a).

\begin{tabular}{|c|c|}
\hline Service Performance Measure & Availability Factor \\
\hline$<50 \%$ & $0 \%$ \\
\hline$\geq 50 \%<75 \%$ & $50 \%$ \\
\hline$\geq 75 \%<95 \%$ & $75 \%$ \\
\hline$\geq 95 \%$ & $100 \%$ \\
\hline
\end{tabular}

\section{Results}

This section summarises the main results of this study, which address the research questions listed in Section 2. Limitations and implications of these results are highlighted in Section 5.

\subsection{Impact of the state-of-charge management strategy}

At the core of this study is a novel state-of-charge (SoC) management strategy which maximises the amount of charging outside of the frequency deadband. This strategy was implemented into the model described in Section 3 and relies on a control algorithm that always targets the lowest possible power response except for when the system frequency is within the deadband. ${ }^{47}$

\footnotetext{
${ }^{45}$ A 1-second delay in response is allowed (NGET, 2016a), hence the s+1 term in (Eq. 9).

46 Note that these can also be revenues, i.e. when energy is discharged while inside the deadband or when EFR utilisation is lower than expected.

47 See algorithm in Section 3.2.1.
} 


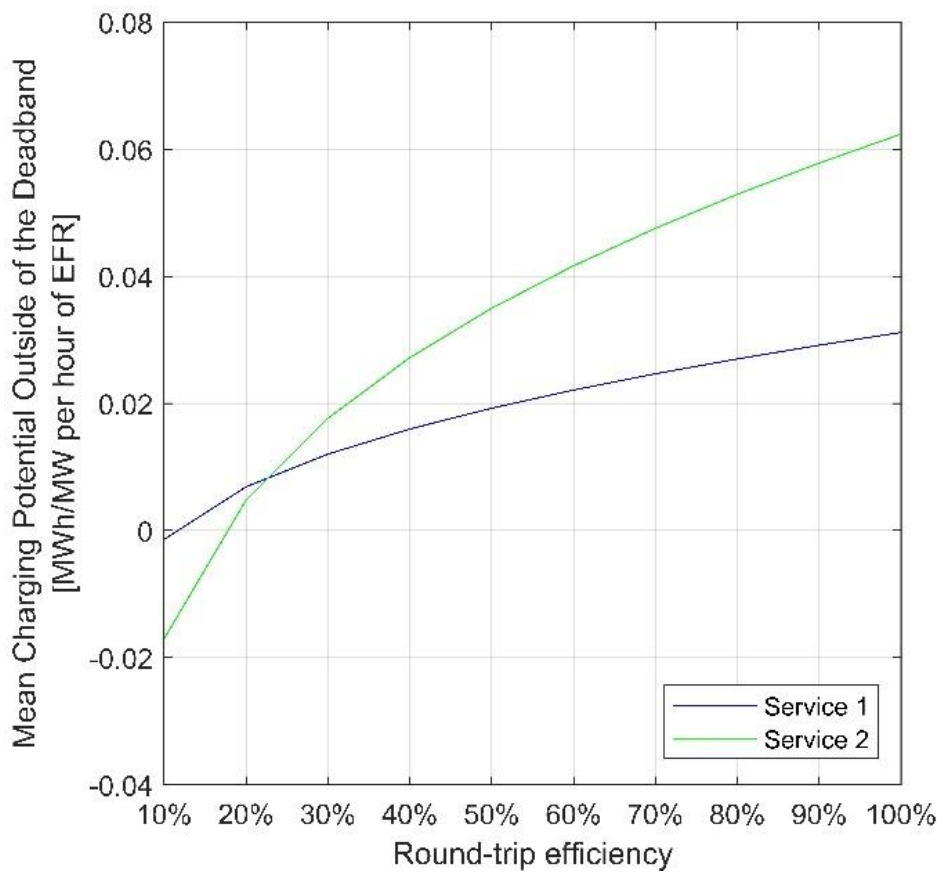

Figure 7 - Mean Charging Potential Outside of the Deadband. ${ }^{48}$

To understand the value of this strategy, the amount of free charging that can be achieved out of the deadband must be computed. The Mean Charging Potential Outside of the Deadband (MCPOD) is here defined as the charge-level increase that can be attained with a 1MW BESS offering a 1-hour EFR availability window (EAW). The theoretical MCPOD is equivalent to the (net) energy exchanged by a BESS delivering a power response that exactly matches the Envelope Lower outside of the deadband, and zero response otherwise. ${ }^{49}$ As shown in Figure 7, a MCPOD of up to $0.063 \mathrm{MWh} / \mathrm{MW}$ per hour is attainable in Service $2,{ }^{50}$ which is to say that the BESS can charge outside of the deadband at an average rate equal to up to $6 \%$ of the contracted power. In other words, free charging through EFR is possible at an average hourly rate of 0.05-0.06 MWh/MW.

\footnotetext{
48 This and the other figures presented here the author's own work, unless otherwise specified.

49 See Figure 2 for the deadband specifications.

50 And of $0.033 \mathrm{MWh} / \mathrm{MW}$ per hour in Service 1. The difference between the two is imputable to the higher share of time inside the deadband for Service 1, which reduces the time available for charging outside of it.
} 


\subsection{Enhanced profitability by alternating EFR and arbitrage}

The techno-economic performance of a 10MW/20MWh Lithium-ion battery was simulated for 600 different EAWs, ${ }^{51}$ with the remainder of the time used for arbitrage. ${ }^{52}$ This energy-topower ratio $^{53}(\mathrm{E} / \mathrm{P}=2 \mathrm{~h})$, which is equivalent to a C-rate of 0.5 , was chosen because the theoretical MCPOD for a $90 \%$-efficient BESS is 0.058 , and over the course of a day this amounts to about $1.4 \mathrm{~h}$ of free charge. Considering that a capacity margin of $0.25 \mathrm{~h}$ at either side is required for compliance with EFR rules, ${ }^{54}$ an $\mathrm{E} / \mathrm{P}$ above $1.9 \mathrm{~h}$ appears like a reasonable first choice.

Figure 8 shows the daily profits ${ }^{55}$ available to the BESS assuming an hourly capacity payment for $E F R$ of $£ 10 / \mathrm{MW}$, based on which baseline profits for EFR-only operations are set to $£ 2,400.56$ Conversely, the average arbitrage profit when no EFR is delivered can be seen to be just under $£ 1,000$. As hypothesised, reducing the EAW duration can increase profits, and in some cases substantially. By pursuing the SoC management strategy devised in this study through January 2017 and alternating EFR with arbitrage, a storage operator could have attained profits of up to $£ 3,434$ per day - a $43.1 \%$ increase compared to the baseline. While only five EAWs allow total profits of $40 \%$ above baseline or more, the average increase in profits for EAWs starting at $7 \mathrm{PM}$ and lasting 9 hours or more is $22.2 \%{ }^{57}$ and that for all EAWs lasting at least 20 hours is $15.8 \%$, which confirms that the opportunity is not confined to a few lucky cases. A synergy between the two services clearly exists.

\footnotetext{
51 Start-time and duration varying between 0AM-23PM and 0-24 h respectively. Service 2 only.

52 The term 'arbitrage' is used loosely in this and the next sections to also describe the case where the BESS solely supplies - but does not buy from - the wholesale market.

${ }^{53}$ Energy to power ratio (E/P) of energy storage is the maximum amount of energy that can be stored in a storage system (MWh) divided by the nominal power rating of the system (MW). E/P with a typical unit of hour (h) is an indication of the capacity of storage relative to the power output, showing the duration of discharge: the higher $\mathrm{E} / \mathrm{P}$ for the same power rating, the longer the discharge time of storage. $\mathrm{E} / \mathrm{P}$ is the reverse of the value of battery C-rate, which is a measure of the rate at which a battery is discharged relative to its maximum capacity.

54 To always be able to handle a 15-min extended frequency event.

55 As pointed out in Section 3.1, fixed operating costs should be detracted to obtain the actual operating profits.

56 To facilitate comparison, SoC management costs and potential penalties for under-delivery are excluded.

${ }^{57}$ For simplicity, the profits are discussed with reference to each EAW provided. However, they also include profits from arbitrage except for durations of $24 \mathrm{~h}$.
} 


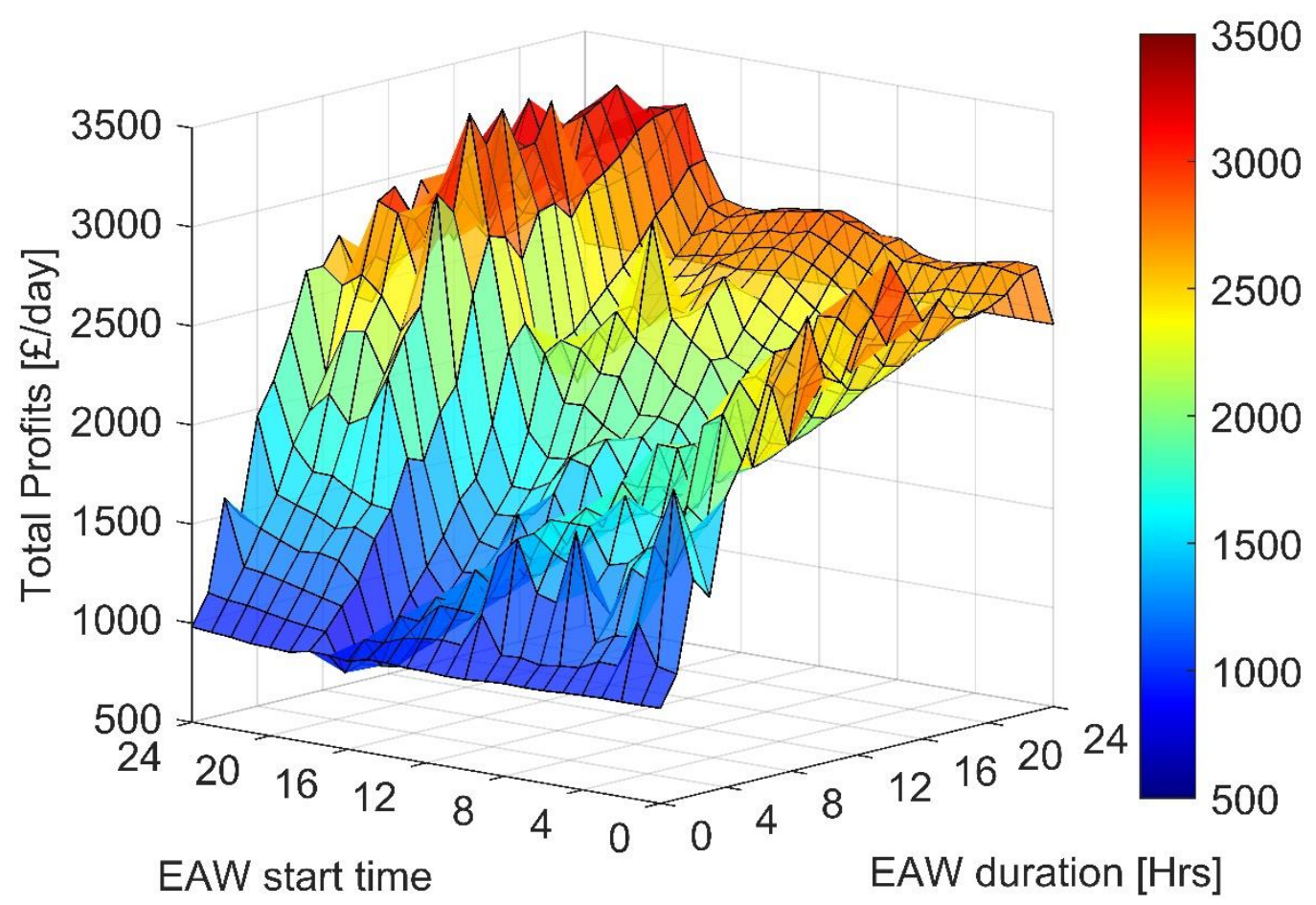

Figure 8 - Daily profits with revenue stacking. Calculated for a 10MW/20MWh Lithium-ion battery operating in January 2017. EAW (enhanced frequency response availability window) starting between 16-20 PM and lasting between 12-18 hours offer the most promising economic profits.

\subsection{Larger energy-to-power ratios lead to larger profits}

The impact of the choice of $\mathrm{E} / \mathrm{P}$ on total operating profits was assessed by re-running the same simulation, but this time with $\mathrm{E} / \mathrm{P}=1.5 \mathrm{~h}$. Figure 9 provides a side-by-side comparison of the two sets of results, highlighting that the $1.5 \mathrm{~h}$ BESS attains substantially reduced profits for all cases except when a 23-hour EAW is offered, in which case the maximum daily profits are highly comparable..$^{5}$ This case can be explained by noting that the time available for discharge is limited to $1 \mathrm{~h}$, whereby increasing the $\mathrm{E} / \mathrm{P}$ above $1.5 \mathrm{~h}$ has virtually no impact. For shorter EAWs however, energy capacity can become a limiting factor, as discussed in Section 5.1.1. An energy-to-power ratio between 1.5 and $2 \mathrm{~h}$ appears to be optimal for leveraging the synergies between arbitrage and EFR. We aim to show the profitability of battery for different values of $\mathrm{E} / \mathrm{P}$, without considering the possible impact of $\mathrm{E} / \mathrm{P}$ on the capital cost of the system. For many BESSs, E/P is typically a function of the chemistry or type of the battery, e.g., E/P of 1-4 for Li-ion versus that of 4-6 for sodium-sulphur batteries. Therefore, while small adjustments in E/P within one battery type may be possible for operational purposes, wider

\footnotetext{
${ }^{58}$ For all start times, although Figure 9 does not highlight this.
} 
adjustments require a different battery type. As such, we examine a range of $\mathrm{E} / \mathrm{P}$ between 1 and $2.5 \mathrm{~h}$.

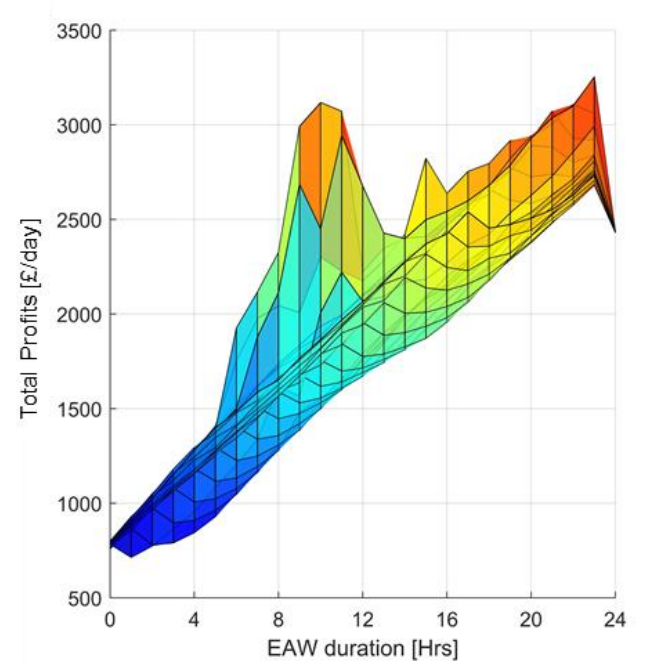

(a) $E / P=1.5 h$

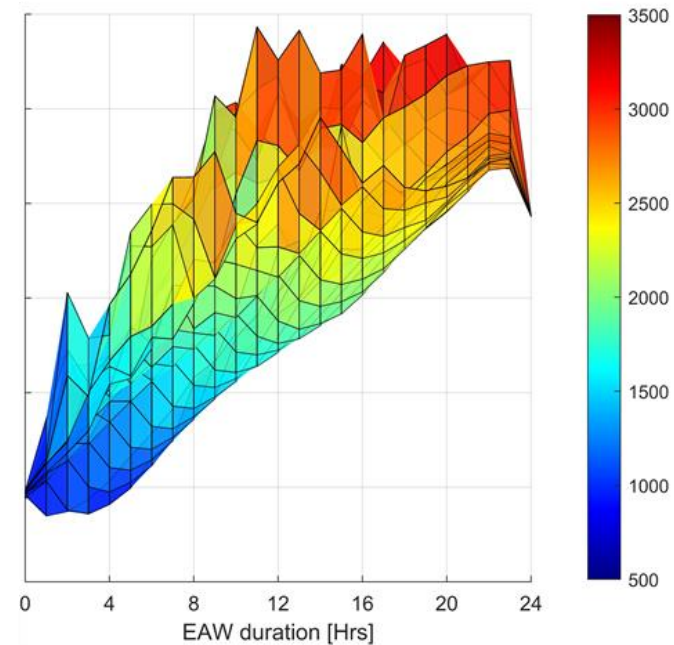

(b) $E / P=2 h$

Figure 9 - Comparison of total daily profits for energy-to-power ratio (E/P) of $1.5 \mathrm{~h}$ and $2 \mathrm{~h}$. The results show that a $2 \mathrm{~h}$ E/P offers a much wider profitability area compared to $1 \mathrm{~h}$. EAW: enhanced frequency response availability window.

\subsection{Seasonal variations: a substantial upside with little downside}

The literature review highlighted that synergies between different services may be affected by seasonal as well as daily variations in market conditions. In the case assessed here, substantial variations occur in the daily electricity price profile, affecting both mean prices and price volatility. To evaluate the impact of seasonal price variations on profits, the performance of the 10MW/20MWh Lithium-ion battery was also evaluated for April 2017 and November 2016. The first period was chosen because of its lower mean price, whereas the second due to its high volatility, which is generally a predictor of arbitrage profits (Wilson et al., 2018).

The profitability of this operating model is robust to seasonal electricity price fluctuations. As can be seen from Figure 10(a), the additional profits attainable through revenue stacking in April 2017 are approximately halved compared to those for January 2017 (Figure 9). Conversely, those for November 2016 (Figure 10b) are almost 3 times as high for the EAWs which do not overlap with the 5-8 PM period, and otherwise comparable. The primary takeaway from this is that EFR-related profits act as a lower-bound and thus limit the 
downside to which storage operators are exposed. At the same time, the exceptional gains achievable in high-volatility periods such as November 2016 are largely preserved. These results also show that the synergy between the two services can be highly discontinuous, which provides a first hint of the synergy's partial dependence on time-varying electricity prices.

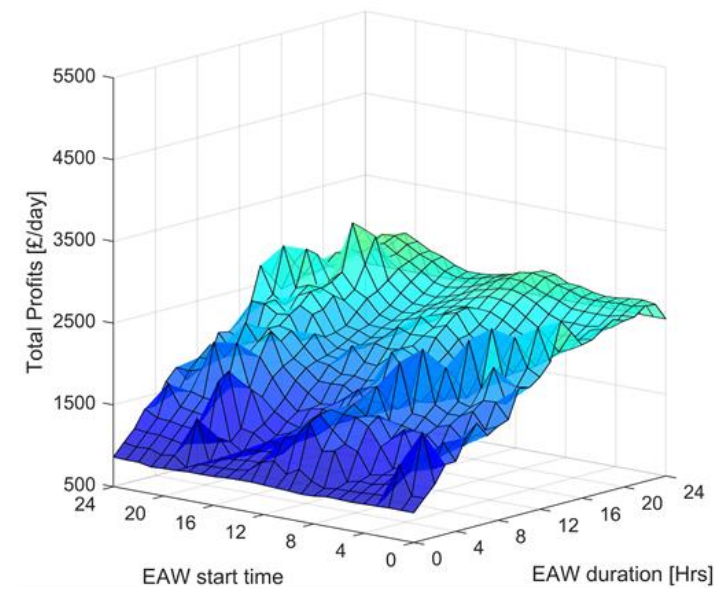

(a) April 2017

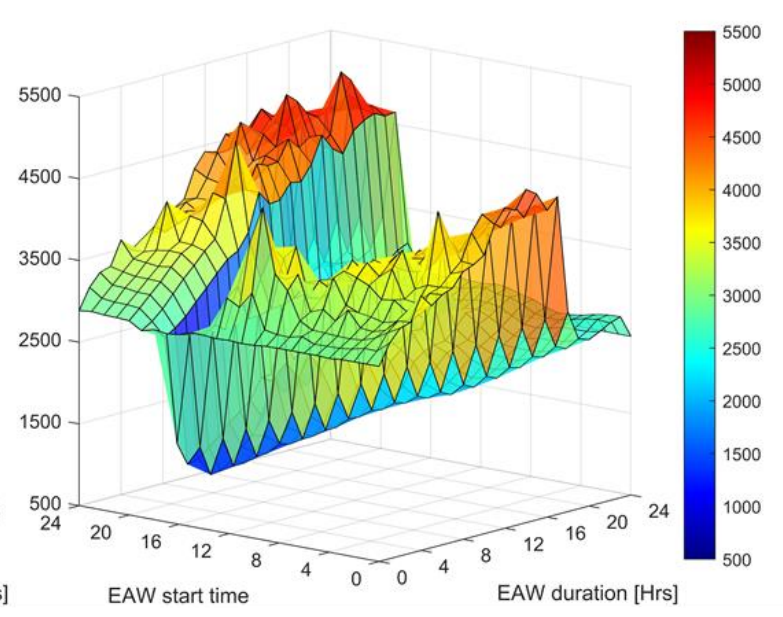

(b) November 2016

Figure 10 - The impact of seasonal variations on profits from revenue stacking. The profitability in April is more strongly correlated to EAW duration rather than the start time. EAW: enhanced frequency response availability window.

\subsection{Type of battery and impact on profitability}

To obtain a more representative average value for the profits that could be attained by a BESS over a longer portion of its lifetime, the time-horizon of the analysis was also extended to 3 years (2015-2017), and the economic performance of both Lithium-ion battery and VRFB was assessed for $\mathrm{E} / \mathrm{P}=1-2.5 \mathrm{~h}$. Building on the insights of the previous sections, the EAW was set to start at $7 \mathrm{PM}$ and last $22 \mathrm{~h}$, which is one of the most valuable windows.

With reference to Figure 11, the longer-term analysis confirms the findings presented above and specifically demonstrates that:

1. Average daily profits of $\sim £ 3,000$ can be expected over the long-term with a $2 \mathrm{~h}$ BESS, both for VRFB and Li-ion. This is an average operating profit increase of $25 \%$ against the EFR-only and 3-times higher revenues against arbitrage-only profits in baseline. This average value is lower than the maximum benefit outlined in the previous section because a longer planning horizon (3 years) is considered, which includes seasonal 
and year-on-year variations in electricity prices that impact the value of arbitrage. Considering the size of the batteries in this analysis, i.e., $20 \mathrm{MWh}$, a profitability of approximately $£ 55 \mathrm{kWh}^{-1}$ per year can be expected. However, the capital cost of the two batteries differs. For a $\mathrm{E} / \mathrm{P}=2$, the capital cost of $\mathrm{Li}$-ion is estimated to be on average $£ 460 \mathrm{kWh}^{-1}$ (Cole et al., 2019), while VRFB costs $£ 410 \mathrm{kWh}^{-1}$ (average value) (Zakeri and Syri, 2015; Rodby et al., 2020). Therefore, a simple payback period of less than 10 years can be expected if the revenues continue to remain the same as today for the lifetime of the batteries.

2. Increasing the $\mathrm{E} / \mathrm{P}$ from $1 \mathrm{~h}$ to up to $2 \mathrm{~h}$ has a substantial impact on operating profits, whereas further increases are much less valuable.

3. Comparing the profitability of VRFB and Li-ion shows that the profitability, especially when $\mathrm{E} / \mathrm{P}=2$, remains very close. There are two main features for these two batteries with counter-balancing impacts on the profitability. VRFB has a lower roundtrip efficiency, $80 \%$ versus $90 \%$ for Li-ion, which results in higher losses and lower revenues for VRFB. On the other hand, VRFB has much longer life cycles, 20,000 versus 5,000 for Li-ion, which results in longer durability, lower replacement numbers, and lower marginal cost of aging for VRFB. As such, these two types of batteries offer comparable profitability for the examined services. 


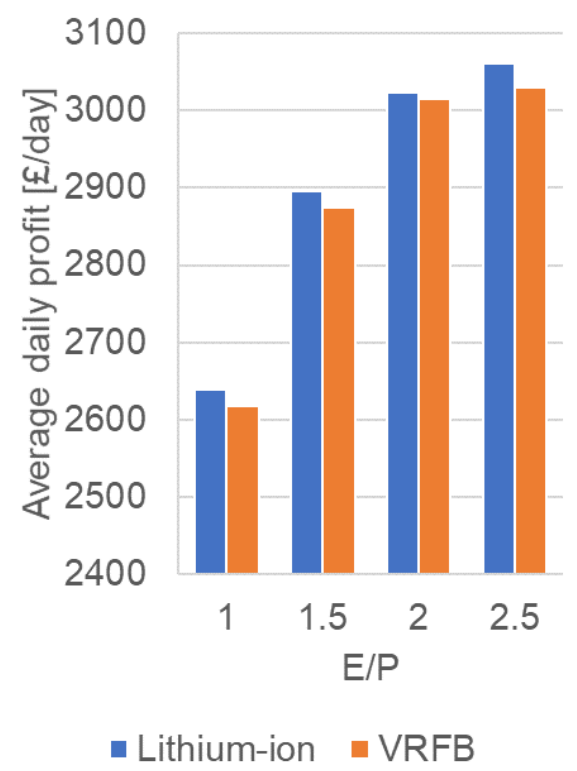

Figure 11 - Average daily profit over 3 years for a $20 \mathrm{MWh}$ battery size. E/P: energy to power ratio of the battery, i.e., $\mathrm{E} / \mathrm{P}$ of 2 means the output power rating is $10 \mathrm{MW}$ for the examined battery.

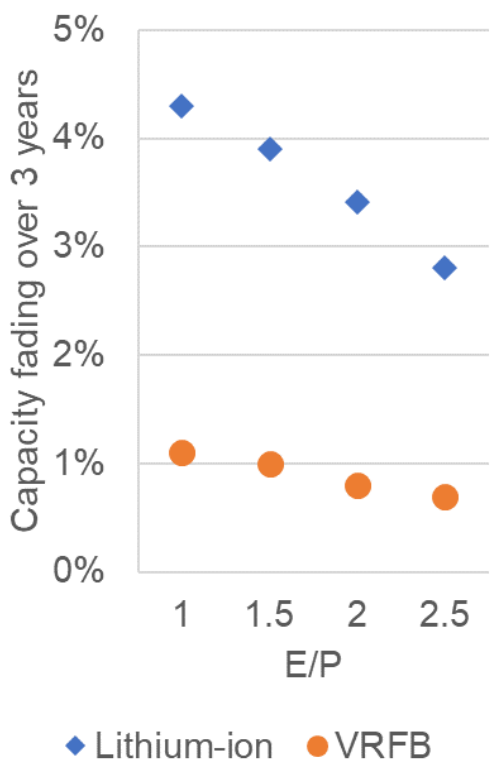

Figure 12 - Discharge capacity fading over 3 years. $\mathrm{E} / \mathrm{P}$ : energy to power ratio of the battery, i.e., $\mathrm{E} / \mathrm{P}$ of 2 means the output power rating is $\mathbf{1 0} \mathrm{MW}$ for a 20 MWh storage capacity.

Figure 12 shows the overall impact of ageing on a BESS's energy capacity over the 3-year period. For VRFBs, this effect is virtually negligible since their lifetime is taken as 20,000 cycles. On the contrary, a Lithium-ion battery with a lifetime of 5,000 cycles would find itself with 3$4 \%$ decreased discharge capacity by the end of the 3 years, which also explains the reducing profitability gap between the two technologies for $\mathrm{E} / \mathrm{P}=2 \mathrm{~h}$. Notably, capacity fades more slowly at higher $\mathrm{E} / \mathrm{P}$, which is reflective of the reduced cycling made possible by the increased energy capacity.

\subsection{A time-dependent optimum for the initial state-of-charge}

Since the SoC management strategy devised in this study is biased towards continuous charging, it would be natural to expect that a low SoC should be targeted at the beginning of each EAW, which would enable the BESS to maximise the free charging potential. The optimal SoC at the beginning of each EAW ( $\left.S_{o} C_{0}\right)$ was computed as part of the simulation ${ }^{59}$ and the corresponding results are displayed in Figure 13. ${ }^{60}$ While these results broadly confirm the

\footnotetext{
${ }^{59}$ For EAW each start-time and duration combination, as discussed in Section 3.3.1.

${ }^{60}$ Results corresponding to the case presented in Section 4.2.
} 
intuition - i.e. a low $S_{0} C_{0}$ is preferred in most cases - there are two exceptions. First, a high $S_{0} C_{0}$ is preferred for short EAWs starting between 5-9 AM and, second, a high $S_{o} C_{0}$ is preferred for all EAWs ending before peak time. ${ }^{61}$ This discontinuity provides yet another hint that the daily variation in electricity prices has an important role to play in shaping the synergies between EFR and arbitrage, a topic which is explored in the next section.

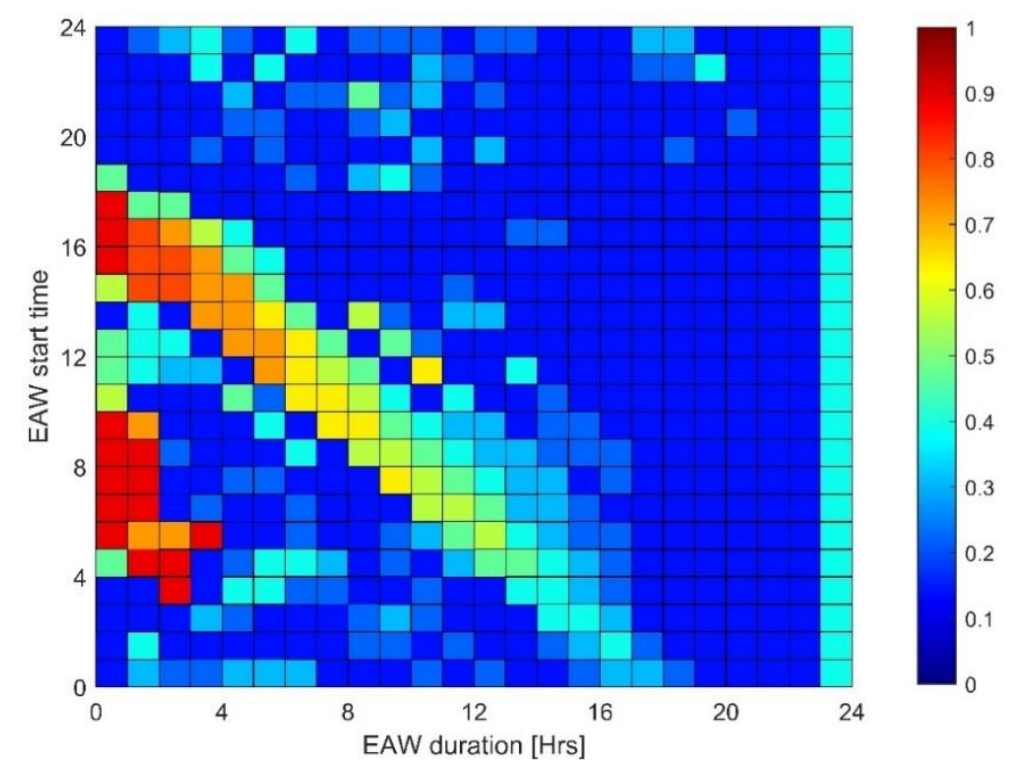

Figure 1 - Variations in the optimal SoC at the start of each frequency resposnse availability window (EAW).

\section{Discussion}

While results only show the aggregate impact of the synergies between EFR and arbitrage on BESS operating profits, there are in fact two distinct synergies:

1. The free charging made possible by this study's SoC management strategy, which can be highly valuable once monetised in the wholesale electricity market; and

2. The fact that arbitrage revenues are concentrated around peak time, whereby discharging the accumulated free charge - or simply ensuring that the BESS is not providing EFR - at this time allows increased asset utilisation.

These synergies are discussed in more detail in the next two sections.

61 These EAWs cut diagonally through Figure 13. 


\subsection{Synergy 1: free charging through EFR}

As shown in Section 4.1, the positive Mean Charging Potential Outside of the Deadband (MCPOD) means that a $10 \mathrm{MW}, 90 \%$-efficient BESS can recharge outside of the deadband and hence for free - at a mean rate of 0.58 MWh for every hour of EFR provided. At an average electricity price of $£ 40.71$ over the 2015-2017 period, ${ }^{62}$ the free charge accumulated over a 22hour EAW would be worth $£ 466$, or $19 \%$ of the $£ 2,400$ baseline for EFR-only revenues. ${ }^{63}$ By comparison, the SoC management strategy devised by Gundogdu et al. (2017b) to conduct arbitrage while offering EFR was demonstrated to increase profits by less than $4 \% .{ }^{64}$

In practice, there are three factors that might decrease the opportunity determined here: a toosmall E/P, which would limit a BESS's ability to exploit this synergy fully; a too-long EAW, which would make it impossible to discharge all of the free energy; and technical limitations, which may prevent a BESS from accurately following the load prescribed by this SoC management strategy. The latter are beyond scope in this study and are only briefly discussed in Section 5.3.

Firstly, it should be noted that the first two points are intrinsically linked, since the E/P selected also sets the time needed to fully discharge the free energy accumulated. Secondly, the optimal E/P is a function of the MCPOD and also of cost factors which are beyond scope. The key implications for BESS sizing are summarised in Figure 14, which shows that energy capacity is a limiting factor in nearly $60 \%$ of days for $\mathrm{E} / \mathrm{P}=1.5 \mathrm{~h}$, a value that drops approximately linearly to $20 \%$ for $\mathrm{E} / \mathrm{P}=2.5 \mathrm{~h}$, which can be attributed to the underlying statistical distribution of the MCPOD (Figure 15).

\footnotetext{
62 Based on N2EX data from (Nord Pool, no date).

63 This is calculated as $22 \mathrm{~h} * 0.58 \mathrm{MWh} / \mathrm{h} * 90 \% * £ 40.71 / \mathrm{MWh}=£ 466$.

${ }^{64}$ They report an increase of up to $7.5 \%$, but since this is calculated against an EFR-only baseline with capacity payments of $£ 5 / \mathrm{MW}$, the magnitude of the improvement is lower when using $£ 10 / \mathrm{MW}$ as reference.
} 


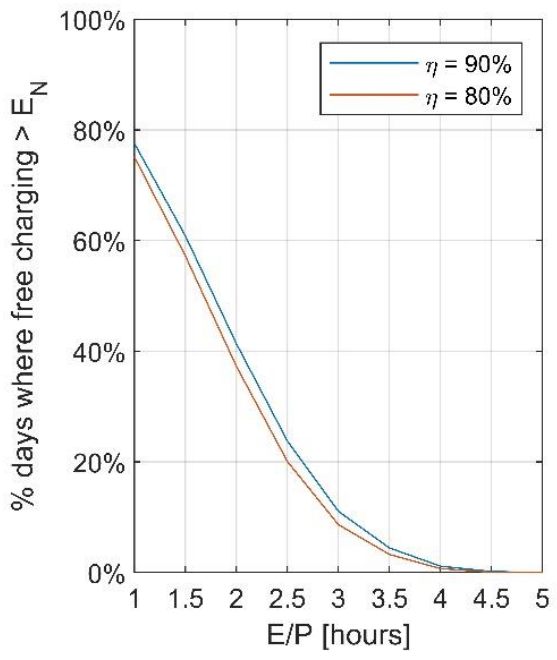

Figure 14 - Capacity constraints due to low energy-to-power ratios. E/P: energy to power ratio of the battery.

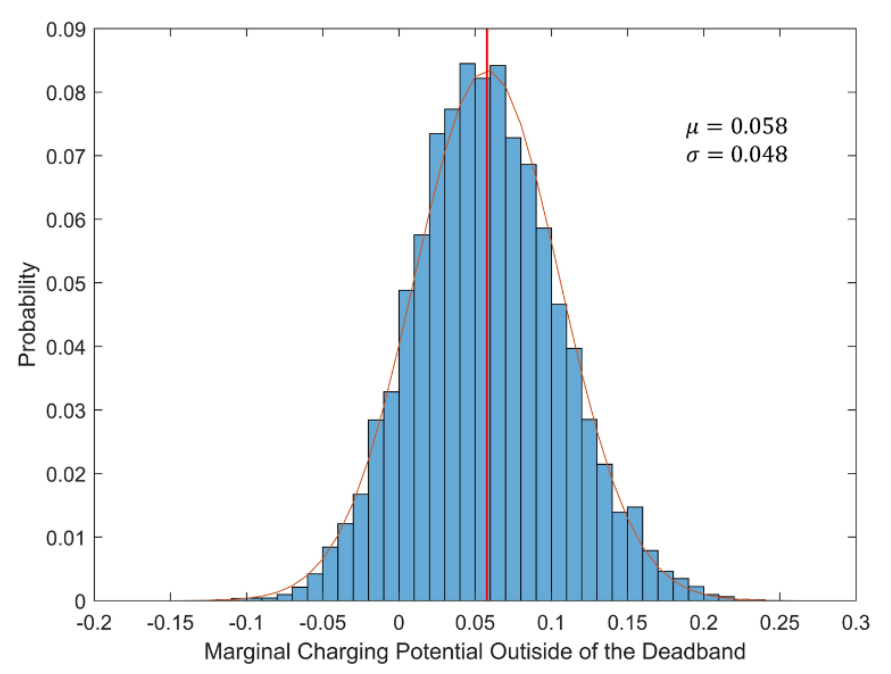

Figure 15 - Histogram of the normally-distributed Mean Charging Potential Outside of the Deadband, based on $\eta_{r t}=\mathbf{9 0} \%$.

\subsubsection{Why energy capacity matters the most}

Figure 14 also hints to the fact that the dependency of storage profits on round-trip efficiency is far less pronounced than that on E/P. This could have also been inferred from Figure 7, which shows that the theoretical MCPOD only decreases by $10 \%$ when efficiency reduces from $90 \%$ to $80 \%$. Since a minimum cap to the total profits is offered by the EFR payments, the impact of a $10 \%$ reduction in MCPOD is simply a similarly-sized reduction in the additional profits of revenue stacking compared to those from EFR alone.

\subsection{Synergy 2: the highly concentrated value of arbitrage}

The second synergy is made possible by the prominent concentration of arbitrage profits around peak time. If the EAW does not fully overlap with peak time, the BESS can capture a high share of the original arbitrage profits without excessive reduction in the EFR capacity payments. Conversely, substantial overlap between the EAW and peak time comes with a high opportunity cost. 

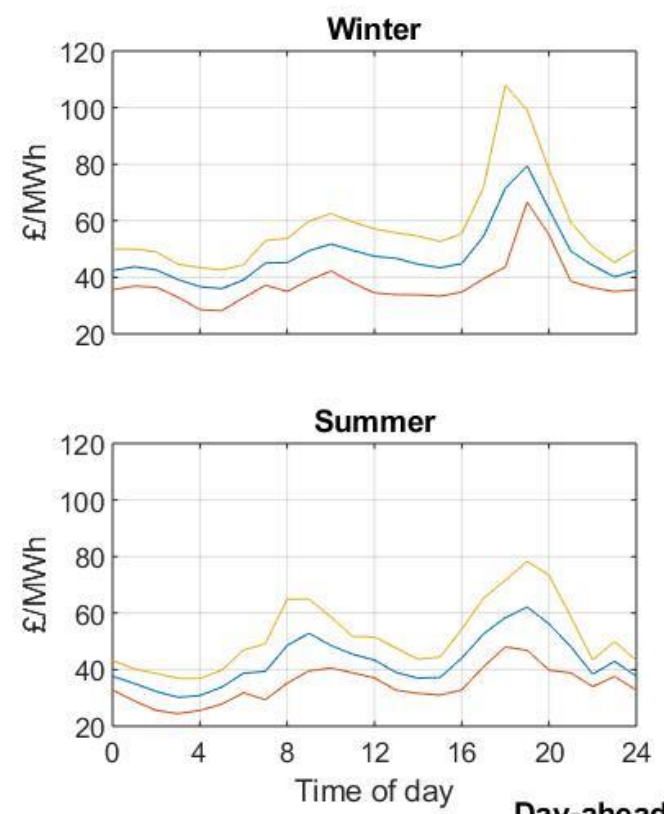

Day-ahead prices by season
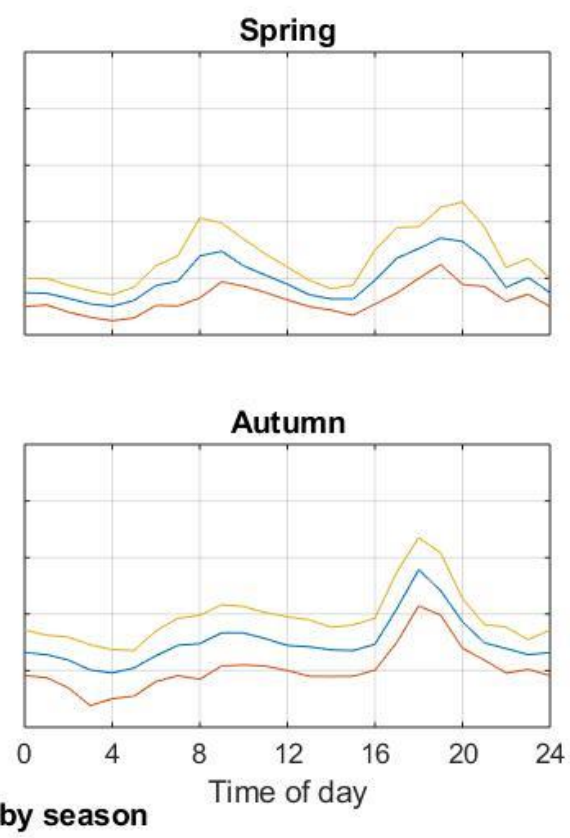

Mean price $-10^{\text {th }}$ percentile $-90^{\text {th }}$ percentile

Figure 16 - Seasonality in British day-ahead prices, based on 2017 N2EX auctions (Nord Pool, 2018) ${ }^{65}$

The high opportunity cost of delivering EFR at peak time is also the reason for the step-change in profits evident in Figure 8, which is shown to typically occur between 6 PM and 7 PM. As show in Figure 16, electricity is most valuable between 5-8 PM in winter, where its average price is around $£ 75 / \mathrm{MWh}$, and the step-change in profits separates EAWs that fully overlap with peak time from those with at least one hour 'free' from EFR. Although one might expect that excluding two of the peak hours from the EAW should be even more valuable, in practice the trade-off between the additional arbitrage profits and the reduced EFR payments limits the extent to which this is true, also considering that on average the MCPOD does not enable more than 1.4 hours' free charging.

This second synergy could increase daily profits by a further $£ 400$ in addition to the first, although the seasonal variations in timing and magnitude of such peak in practice limit the attainable value over the longer term to around $£ 150 .{ }^{66}$

\footnotetext{
65 Time of day expressed in Greenwich Mean Time (GMT) for consistency.

66 i.e. The difference between the $25 \%$ improvement demonstrated over the 3 -year period in Section 4.4 , and the $19 \%$ improvement imputable to the first synergy alone using average electricity prices.
} 
It is also interesting to note that whenever the BESS can discharge for at least one hour between 5-8PM, the increase in profits seemingly matches the baseline arbitrage profits attained when no EFR is offered. Figure 17 confirms that the BESS is indeed able to attain even greater arbitrage-only profits on the day-ahead market when EFR is provided, which clearly indicates a synergy between the two services that goes beyond the inclusion or exclusion of peak time, and which can be attributed to the SoC management strategy.

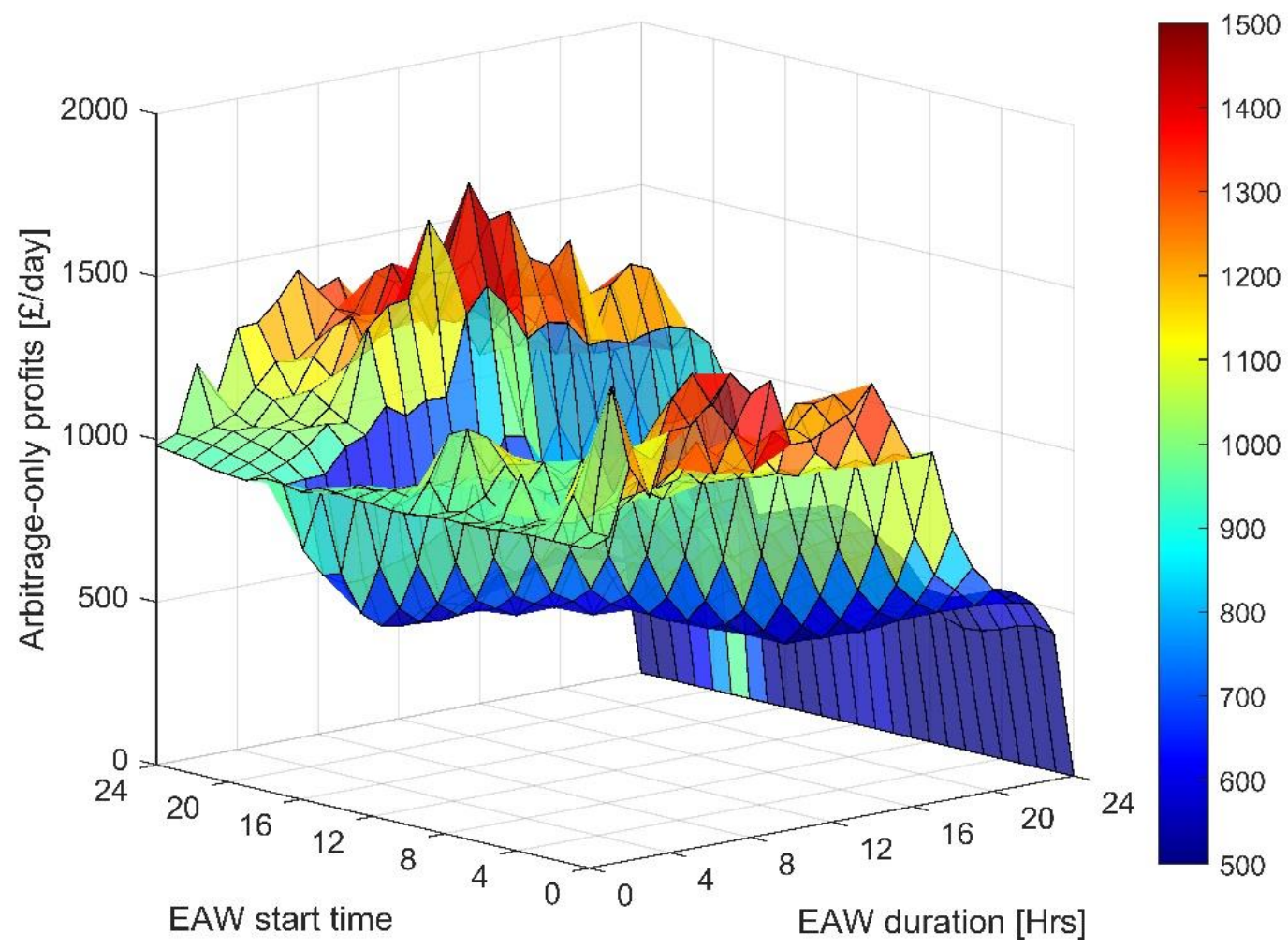

Figure 17 - Arbitrage-only profits of battery energy storage when providing enhanced frequency response as well. EAW: enhanced frequency response availability window.

Finally, the substantial volatility in profits ${ }^{67}$ visible across neighbouring EAWs in all of the previous figures is due to the short timescale used for the simulation (1 month). A far smoother picture would be obtained by replicating the same analysis over a 1-year period.

\subsubsection{Impact of the strategy on optimal SoC at start of each availability window}

The daily variation in electricity prices is also the reason behind differences presented in Section 4.5 in the optimal SoC at the start of different EAWs $\left(\operatorname{SoC}_{0}\right)$. Specifically, it is most

\footnotetext{
${ }^{67}$ Marginal operating profit favours arbitrage over time as the battery ages given the lower response time..
} 
convenient for the BESS to charge during the morning trough in electricity prices occurring between 3-5 AM, which is why a higher $S_{o} C_{0}$ is optimal for short-duration EAWs starting soon after. Similarly, the characteristic 5-8 PM peak is the reason why a high $S_{0} C_{0}$ is also preferable for all short EAWs ending before it. In this case, it is optimal to reach the highest possible charge level by the end of the EAW since discharge at peak time is highly valuable. As for the $24 \mathrm{~h}$ case, this is an outlier since the initial SoC is only used once - at the beginning of the simulation - and never thereafter. In this case, the proposed SoC management strategy leads to a SoC which stabilises around the upper SoC threshold required for EFR compliance. ${ }^{68}$ Thus, the total profits are very similar for this limit case regardless of the exact value for $\mathrm{SoC}_{0}$.

\subsection{Limitations and potential improvements}

While the model built for this study aimed to cover all of the key factors affecting the technoeconomic performance of a BESS offering EFR and arbitrage, improvements to the model could enhance accuracy of results. These are discussed next.

\subsubsection{Which ramp-rates in real life?}

Although the literature suggests that the ramp-rates required for this operating model to work are attainable, ${ }^{69} \mathrm{it}$ is possible that real-life testing will reveal limits to how accurately the SoC management strategy proposed here can be pursued. If so, the trade-off between the benefits of this strategy and the risk of incurring penalties for under-delivery would need to be carefully weighted. Even then, the benefits of the second synergy discussed in Section 5.2 could likely be exploited through an amended operating model.

\subsubsection{Perfect foresight: a simplifying assumption that estimates arbitrage profitability}

As noted by Staffell and Rustomji (2016), only a (high) portion of the arbitrage profits calculated with perfect foresight can be attained in practice. They report that, with a simple price-forecasting method solely based on historical data, $75 \%$ of the perfect-foresight profits could be attained in the case of an $80 \%$-efficient BESS only delivering arbitrage. Staffell and

\footnotetext{
68 See Section 3.3.1.

69 Which fully comply with EFR rules, as shown in Appendix 3.
} 
Rustomji however also note that when arbitrage is provided as part of a revenue stacking configuration the proportion of attainable profits can rise to $96 \%$ for the same BESS.

The perfect foresight assumption would hardly affect the value of providing long EAWs (e.g. 22-23 h), since in this case the arbitrage optimisation algorithm has either limited or no choice over which hour to select for discharging.

Nonetheless, the use of stochastic optimisation techniques might reveal that the additional profits over those from EFR-only could be lower than modelled here, which would reinforce the preference for long EAWs.

\subsubsection{Improvements to the techno-economic model}

Improvements to the techno-economic model could also be beneficial to enhance the accuracy of results. More accurate modelling of the ageing phenomenon and related costs would be useful to improve the arbitrage scheduling decision (Xu et al., 2017) and also to help determine whether long-lived technologies such as VRFBs or the faster-ageing Lithium-ion batteries offer the best value for money for this operating model.

Similarly, round-trip efficiency was modelled as being constant, but in practice this parameter often depends on the power density, among other factors. Hence, unless a BESS is optimised for EFR operations, additional efficiency losses might erode the attainable free charging to the extent shown in Figure 7.

\subsubsection{The effect of ignoring market readjustments}

Finally, the assumptions that the BESS is a price-taker and that its behaviour while delivering EFR has no impact on the system frequency are obvious simplifications. The depressing impact of the operating model on day-ahead prices could be assessed through econometric estimation of the price elasticity of the electricity demand and supply curves, whereas the impact on system frequency would entail a more detailed model of the time-varying inertia which characterises the electricity system. ${ }^{70}$

\footnotetext{
${ }^{70}$ EFR has been abandoned and there is currently no market designed with the characetristics of storage in mind (Castagneto Gissey et al., 2017).
} 


\subsubsection{Suggestions for further work}

Multiple streams of works could follow the present study. The approach set out here could be extended to investigate the potential value of stacking EFR with services other than arbitrage. For instance, both Triad avoidance and peak shaving might value the free energy that can be gained with the proposed SoC management strategy. This approach might also have some potential for services with less predictable demand patterns, such as when the BESS is colocated with wind or solar farms. In this case, the BESS could be treated as the modular asset that it often is, whereby the power and energy capacities could be virtually split across the different purposes to enable maximum asset utilisation and hence maximum profitability.

It would also be useful to develop ways for Transmission System Operators to enable this and other revenue stacking models with EFR. Some ideas on this are in Appendix 6.

Finally, upfront and fixed operating costs were left aside since they do not affect the operational strategy. Integrating these within the model would enable an assessment of the multiple economic trade-offs highlighted above, among which that between larger energy-topower ratios and higher upfront cost is most critical.

\section{Conclusions}

This study set out to assess the potential synergies between the provision of Enhanced Frequency Response (EFR) and arbitrage in the wholesale electricity market with a battery energy storage system (BESS). The second-by-second operation of the BESS through EFR and the hourly optimisation for arbitrage was simulated though a bespoke techno-economic model. Using historical data for Great Britain during 2015-2017, and after assessing 600 EFR availability windows, this study showed that two separate synergies exist between the two revenue streams.

The first synergy relies on the fact that a BESS can recharge outside of the deadband, hence for free, at an average rate between 0.05-0.96 MWh for every hour of EFR provided and for each MW of capacity. ${ }^{71}$ The Mean Charging Potential Outside of the Deadband (MCPOD) was

\footnotetext{
${ }^{71}$ For typical BESS efficiencies of $80-90 \%$. This is possible thanks to the tolerance margins in the response to system frequency deviations contemplated by EFR rules.
} 
defined accordingly, and the implications deriving from its statistical properties were investigated. To benefit from this first synergy, a storage operator would simply need to alternate EFR with a few hours' breaks during which the accumulated energy is discharged. For a $22 \mathrm{~h}$ availability window starting at 7 PM and with a 10 MW BESS, this was estimated to be worth around $£ 450$ per day on average over a 3-year period.

The second synergy instead occurs because arbitrage revenues are highly concentrated around peak-time. Thus, interrupting EFR provision at that time can enable a BESS to capture most of the arbitrage revenues without excessive reduction in the EFR capacity payments. For the 10 MW BESS, this synergy was found to be worth $£ 150$ per day on average.

The combination of these two synergies means that a 10 MW BESS using the operating strategy proposed in this study could have earned around $£ 3,000$ per day, or $25 \%$ more compared to providing EFR alone over the period 2015-2018. ${ }^{72}$ Considering the capital cost of the batteries in 2018, this profitability offers a payback period of less than 10 years for the examined batteries. The long timeframe assessed suggests the robustness of results to seasonal electricity price fluctuations. This robustness is a key property of the proposed model and is largely possible thanks to the EFR capacity payments, which act as a lower-bound for daily profits while the BESS can still capture large arbitrage profits during periods of high price volatility if the second synergy is leveraged.

Finally, it was found that the energy-to-power ratio $(\mathrm{E} / \mathrm{P})$, rather than discharge efficiency, is a key driver of profitability for this operating model. Although the optimal E/P to take advantage of the above synergies is expected to lie between 1.5-2 $\mathrm{h}$, a cost model able to capture the economic trade-offs between the various technical parameters would be required to reach a firm conclusion on this point.

The main recommendation is for storage operators to implement the operating model of this study in order to improve the business case for BESSs. This would encourage the deployment of BESSs, making the electricity system more secure, sustainable and affordable.

\section{Acknowledgments}

\footnotetext{
${ }^{72}$ Quantified as $£ 2,400$ based on a capacity payment of $£ 10 / \mathrm{MW}$ per hour.
} 
This research was funded by the UK Engineering and Physical Sciences Research Council (EPSRC) and InnovateUK through the ICE (EP/R021333/1) and RESTLESS (EP/N001893/1) projects. Contribution of BZ were supported by Aalborg University, Denmark, and International Institute for Applied Systems Analysis (IIASA). We thank the anonymous reviewers for their valuable comments on our manuscript.

\section{References}

Bahloul, M. and Khadem, S. K. (2018) 'Design and control of energy storage system for enhanced frequency response grid service', in 2018 IEEE International Conference on Industrial Technology (ICIT). IEEE, pp. 1189-1194. doi: 10.1109/ICIT.2018.8352347.

Beaudin, M. et al. (2010) 'Energy storage for mitigating the variability of renewable electricity sources: An updated review', Energy for Sustainable Development. Elsevier Inc., 14(4), pp. 302314. doi: 10.1016/j.esd.2010.09.007.

Belli, G. et al. (2017) 'Imbalances costs of small scale renewable not dispatchable power plants in the Italian electricity market', in 2017 14th International Conference on the European Energy Market (EEM). IEEE, pp. 1-6. doi: 10.1109/EEM.2017.7981895.

Canevese, S. et al. (2017) 'Simulation of enhanced frequency response by battery storage systems: The UK versus the continental europe system', in 2017 IEEE International Conference on Environment and Electrical Engineering and 2017 IEEE Industrial and Commercial Power Systems Europe (EEEIC / IECPS Europe). IEEE, pp. 1-6. doi: 10.1109/EEEIC.2017.7977789.

Castagneto Gissey, G., Dodds, P. E. and Radcliffe, J. (2018) ‘Market and regulatory barriers to electrical energy storage innovation', Renewable and Sustainable Energy Reviews, 82, pp. 781790. doi: https://doi.org/10.1016/j.rser.2017.09.079.

Chen, H. et al. (2016) 'Optimization of energy storage system capacity for wind farms based on cost-benefit analysis', in 2016 IEEE PES Asia-Pacific Power and Energy Engineering Conference (APPEEC). IEEE, pp. 1513-1517. doi: 10.1109/APPEEC.2016.7779743.

Cheng, M., Sami, S. S. and Wu, J. (2017) 'Benefits of using virtual energy storage system for power system frequency response', Applied Energy, 194, pp. 376-385. doi: https://doi.org/10.1016/j.apenergy.2016.06.113.

Cho, J. and Kleit, A. N. (2015) 'Energy storage systems in energy and ancillary markets: A backwards induction approach', Applied Energy. Elsevier Ltd, 147, pp. 176-183. doi: 10.1016/j.apenergy.2015.01.114.

Cole, W.J. and Frazier, A., 2019. Cost projections for utility-scale battery storage (No. NREL/TP6A20-73222). National Renewable Energy Lab.(NREL), Golden, CO (United States).

Cooke, A., Strickland, D. and Forkasiewicz, K. (2017) 'Energy storage for enhanced frequency response services', in 2017 52nd International Universities Power Engineering Conference, UPEC 
2017. Institute of Electrical and Electronics Engineers Inc., pp. 1-6. doi: 10.1109/UPEC.2017.8231914.

Critchlow, J. and Denman, A. (2017) 'Embracing the Next Energy Revolution: Electricity Storage'.

ELEXON (no date) Detailed System Prices I BMRS.

Fong, G., Moreira, R. and Strbac, G. (2017) 'Economic analysis of energy storage business models', in 2017 IEEE Manchester PowerTech. IEEE, pp. 1-6. doi: 10.1109/PTC.2017.7980829.

Goutte, S. and Vassilopoulos, P. (2019) 'The value of flexibility in power markets', Energy Policy. Elsevier Ltd, 125, pp. 347-357. doi: 10.1016/j.enpol.2018.10.024.

Greenwood, D. M. et al. (2017) 'Frequency response services designed for energy storage', Applied Energy, 203, pp. 115-127. doi: https://doi.org/10.1016/j.apenergy.2017.06.046.

Gundogdu, B. et al. (2017) 'A battery energy management strategy for UK enhanced frequency response', in 2017 IEEE 26th International Symposium on Industrial Electronics (ISIE). IEEE, pp. 26-31. doi: 10.1109/ISIE.2017.8001218.

Gundogdu, B. et al. (2018) 'A Battery Energy Management Strategy for UK Enhanced Frequency Response and Triad Avoidance', IEEE Transactions on Industrial Electronics, 65(12), pp. 9509-9517. doi: 10.1109/TIE.2018.2818642.

Gundogdu, B., Gladwin, D. T. and Stone, D. A. (2017) ‘Battery SOC management strategy for enhanced frequency response and day-ahead energy scheduling of BESS for energy arbitrage', in IECON 2017 - 43rd Annual Conference of the IEEE Industrial Electronics Society. IEEE, pp. 76357640. doi: 10.1109/IECON.2017.8217338.

He, G. et al. (2020) 'The economic end of life of electrochemical energy storage', Applied Energy, 273, p. 115151. doi: https://doi.org/10.1016/j.apenergy.2020.115151.

He, L. et al. (2018) 'A flexible power control strategy for hybrid AC/DC zones of shipboard power system with distributed energy storages', IEEE Transactions on Industrial Informatics. IEEE Computer Society, 14(12), pp. 5496-5508. doi: 10.1109/TII.2018.2849201.

Hesse, H. et al. (2017) 'Economic Optimization of Component Sizing for Residential Battery Storage Systems', Energies. Multidisciplinary Digital Publishing Institute, 10(7), p. 835. doi: 10.3390/en10070835.

Hollinger, R., Cortés, A. M. and Erge, T. (2018) 'Fast Frequency Response with BESS: A Comparative Analysis of Germany, Great Britain and Sweden', International Conference on the European Energy Market, EEM. doi: 10.1109/EEM.2018.8469998.

IRENA (2017) Electricity storage and renewables: Costs and markets to 2030.

Korpaas, M., Holen, A. T. and Hildrum, R. (2003) ‘Operation and sizing of energy storage for wind power plants in a market system', International Journal of Electrical Power \& Energy 
Systems. Elsevier, 25(8), pp. 599-606. doi: 10.1016/S0142-0615(03)00016-4.

KPMG Energy Advisory (2016) EFR tender results.

Kreikebaum, F. et al. (2011) 'Evaluating the application of energy storage and day-ahead solar forecasting to firm the output of a photovoltaic plant', in 2011 IEEE Energy Conversion Congress and Exposition. IEEE, pp. 3556-3561. doi: 10.1109/ECCE.2011.6064250.

Li, C. et al. (2015) 'Comprehensive review of renewable energy curtailment and avoidance: A specific example in China', Renewable and Sustainable Energy Reviews. Pergamon, 41, pp. 10671079. doi: 10.1016/J.RSER.2014.09.009.

Li, Y. et al. (2018) 'A dynamic coordinated control strategy of WTG-ES combined system for short-term frequency support', Renewable Energy. Elsevier Ltd, 119, pp. 1-11. doi: 10.1016/j.renene.2017.11.064.

Logic Energy (2019) What is Enhanced Frequency Response and Which Are Its Benefits? Available at: https://www.logicenergy.com/post/what-is-enhanced-frequency-response-and-whichare-its-benefits (Accessed: 31 October 2020).

Loisel, R. et al. (2010) 'Valuation framework for large scale electricity storage in a case with wind curtailment', Energy Efficiency Policies and Strategies with regular papers., 38(11), pp. 73237337. doi: http://dx.doi.org/10.1016/j.enpol.2010.08.007.

Lund, H. et al. (2009) 'Optimal operation strategies of compressed air energy storage (CAES) on electricity spot markets with fluctuating prices', Applied Thermal Engineering. Affiliation: Department of Development and Planning, Aalborg University, Fibigerstraede 13, DK-9220, Denmark; Affiliation: Department of Mechanical Engineering, Technical University of Denmark, Kongens, Lyngby, Denmark; Affiliation: EMD International A/S, 29(5-6), pp. 799806. Available at: http://www.scopus.com/inward/record.url?eid=2-s2.0$58549115048 \&$ partnerID=40\&md5=45ace1e6f38add029fff41c3765b37d0.

Lund, P. D. et al. (2015) 'Review of energy system flexibility measures to enable high levels of variable renewable electricity', Renewable and Sustainable Energy Reviews. Elsevier, 45, pp. 785807. doi: 10.1016/j.rser.2015.01.057.

Luo, X. et al. (2015) 'Overview of current development in electrical energy storage technologies and the application potential in power system operation', Applied Energy. Elsevier Ltd, 137, pp. 511-536. doi: 10.1016/j.apenergy.2014.09.081.

Merten, M. et al. (2020) 'Automatic frequency restoration reserve market prediction: Methodology and comparison of various approaches', Applied Energy, 268, p. 114978. doi: https://doi.org/10.1016/j.apenergy.2020.114978.

Metz, D. and Saraiva, J. T. (2018) ‘Use of battery storage systems for price arbitrage operations in the 15- and 60-min German intraday markets', Electric Power Systems Research. Elsevier, 160, pp. 27-36. doi: 10.1016/j.epsr.2018.01.020.

Minke, C., Kunz, U. and Turek, T. (2017) 'Techno-economic assessment of novel vanadium 
redox flow batteries with large-area cells', Journal of Power Sources. Elsevier B.V, 361, pp. 105114. doi: 10.1016/j.jpowsour.2017.06.066.

Moreira, R., Moreno, R. and Strbac, G. (2016) 'Synergies and conflicts among energy storage services', in 2016 IEEE International Energy Conference (ENERGYCON). IEEE, pp. 1-6. doi: 10.1109/ENERGYCON.2016.7513945.

Moreno, R., Moreira, R. and Strbac, G. (2015) 'A MILP model for optimising multi-service portfolios of distributed energy storage', Applied Energy, 137, pp. 554-566. doi: http://dx.doi.org/10.1016/j.apenergy.2014.08.080.

NGET (2016a) Enhanced Frequency Response. Invitation to tender for pre-qualified parties. National Grid.

NGET (2016b) Enhanced Frequency Response market information report. National Grid.

NGET (2018a) ‘Faster Acting Response, Industry Workshop’. National Grid.

NGET (2018b) 'System Needs and Product Strategy (slides)'. National Grid.

NGET (no date) Historic frequency data. National Grid.

Nord Pool (no date) ‘Historical Market Data'.

Oldenburg, F. J., Schmidt, T. J. and Gubler, L. (2017) 'Tackling capacity fading in vanadium flow batteries with amphoteric membranes', Journal of Power Sources. Elsevier B.V, 368, pp. 6872. doi: 10.1016/j.jpowsour.2017.09.051.

Poudineh, R. and Jamasb, T. (2014) 'Distributed generation, storage, demand response and energy efficiency as alternatives to grid capacity enhancement', Energy Policy. Elsevier, 67, pp. 222-231. doi: 10.1016/j.enpol.2013.11.073.

Rodby, K. E. et al. (2020) 'Assessing the levelized cost of vanadium redox flow batteries with capacity fade and rebalancing', Journal of Power Sources. Elsevier B.V., 460, p. 227958. doi: 10.1016/j.jpowsour.2020.227958.

Saravanan, B. et al. (2013) 'A solution to the unit commitment problem - a review', Frontiers in Energy. SP Higher Education Press, 7(2), pp. 223-236. doi: 10.1007/s11708-013-0240-3.

Schmidt, O. et al. (2017) 'The future cost of electrical energy storage based on experience rates', Nature Energy, 2(8), pp. 1-8. doi: 10.1038/nenergy.2017.110.

Shi, Y. et al. (2017) ‘Using Battery Storage for Peak Shaving and Frequency Regulation: Joint Optimization for Superlinear Gains', IEEE Transactions on Power Systems, pp. 1-1. doi: 10.1109/TPWRS.2017.2749512.

Sioshansi, R. et al. (2009) 'Estimating the value of electricity storage in PJM: Arbitrage and some welfare effects', Energy Economics. Affiliation: Industrial, Welding, and Systems Engineering Department, The Ohio State University, United States; Affiliation: National 
Renewable Energy Laboratory, United States; Affiliation: Point Carbon North America, United States, 31(2), pp. 269-277. Available at: http://www.scopus.com/inward/record.url?eid=2-s2.0$58749113229 \&$ partnerID=40\&md5=a616fe593437dbf814cfae61c3991477.

de Sisternes, F. J., Jenkins, J. D. and Botterud, A. (2016) 'The value of energy storage in decarbonizing the electricity sector', Applied Energy. Elsevier Ltd, 175, pp. 368-379. doi: 10.1016/j.apenergy.2016.05.014.

Staffell, I. and Rustomji, M. (2016) 'Maximising the value of electricity storage', Journal of Energy Storage. Elsevier Ltd, 8, pp. 212-225. doi: 10.1016/j.est.2016.08.010.

Strbac, G. et al. (2012) Strategic Assessment of the Role and Value of Energy Storage Systems in the UK Low Carbon Energy Future.

Teng, F. and Strbac, G. (2016) 'Business cases for energy storage with multiple service provision', Journal of Modern Power Systems and Clean Energy. Springer Heidelberg, 4(4), pp. 615-625. doi: 10.1007/s40565-016-0244-1.

Wilson, I. A. G. et al. (2018) 'An analysis of storage revenues from the time-shifting of electrical energy in Germany and Great Britain from 2010 to 2016', Journal of Energy Storage. Elsevier, 17, pp. 446-456. doi: 10.1016/J.EST.2018.04.005.

Xu, B. et al. (2017) 'Factoring the Cycle Aging Cost of Batteries Participating in Electricity Markets'.

Zafirakis, D. et al. (no date) 'The value of arbitrage for energy storage: Evidence from European electricity markets', Applied Energy. doi: http://dx.doi.org/10.1016/j.apenergy.2016.05.047.

Zakeri, B. and Syri, S. (2015) 'Electrical energy storage systems: A comparative life cycle cost analysis', Renewable and Sustainable Energy Reviews, 42. doi: 10.1016/j.rser.2014.10.011. 